\title{
Believing in Economic Theory: Sex, Lies, Evidence, Trust and Ideology
}

Abstract. In many empirical studies, ideology significantly predicts political outcomes, even after controlling for interests. This may reflect ideology's influence on descriptive beliefs about the workings of the economic world. We investigate these beliefs about supply and demand theory, using survey methods and an experimental demonstration. As expected, relatively liberal respondents have more skeptical ex-ante beliefs (before viewing the experiment) about the theory. Surprisingly, however, relatively conservative respondents update beliefs (after viewing the experiment) so much less strongly that they have more skeptical ex-post beliefs. We explore and discount alternative explanations for these relationships between ideology and beliefs.

First draft: October 2003. This revision: October 2004.

Acknowledgments. We have benefited from comments and help from Sarah Austin, Thilo Bodenstein, Dirk Engelmann, Jan Kmenta, Kathleen Knight, John Matsusaka, Andreas Ortmann and Christopher Wlezien, as well as seminar participants at the Public Choice/Economic Science Association meetings in San Antonio, Economic Science Association meetings in Barcelona and Tucson, the European Economic Association meetings in Venice, the California Institute of Technology, Technische Universität Chemnitz and the Max Planck Institut Strategic Interaction Group in Jena. Of course, none of these people are responsible for remaining errors or ambiguities. 
Beliefs about how well economic theory describes actual economic behavior may affect policy through democratic political processes. Understanding what affects these beliefs is therefore critical to understanding forces that shape and constrain economic institutions and policies in democracies. We investigate how individual attitudes and characteristics correlate with those beliefs by having people watch a Double Auction experiment, combined with a survey and ex-ante and ex-post elicitations of beliefs about how well supply and demand theory will predict economic outcomes in the experiment. We find that ideology has a significant and sometimes surprising relationship to those beliefs about economic theory's descriptive content.

In policy analysis, economic theory provides a strong justification for separating policies for efficiency and distribution (Diamond and Mirlees 1971). This framework recognizes that views of the "proper" distribution of buying power differ, and that these differences can be resolved within the realm of politics through appropriate distributional policies such as tax policies. Obviously ideology may be related to these differing views of distribution, so it would be unsurprising if democratic politics produced relationships between observed distributional policies and the ideological composition of electorates. On the other hand, this framework argues for agreement on the common goal of efficiency. Assuming that there is widespread agreement in the electorate as to how people actually behave within economic institutions, and how government interventions mediate that behavior, acceptance of this efficiency goal implies that ideology will play no role in determining economic policies aimed at efficiency.

Obviously, Diamond and Mirlees (1971) did not mean their framework to be taken as descriptive of actual economic policies. Politicians often ignore its policy prescriptions (Haveman 1976). Yet the divergence of actual policy from policy advice prompted several generations of economists and political scientists to explain it. Public choice researchers argue 
that this is a consequence of democratic politics: the interaction of self-interested citizens with diverse interests, who vote, lobby, contribute to campaigns and form coalitions, will not produce the policies of a hypothetical social planner. Downs's economic theory of democracy (1957) and Stigler's theory of economic regulation (1971) are two early examples of this approach. Selfinterested competition among interest groups and individuals probably explains much about policymaking, and various empirical analyses support this view (Winston 1993).

It has also been argued, of course, that diversity of self-interests may sometimes be oversold as a determinant of actual policies. Even Stigler (1965) had once thought that policy makers might be trying to promote the general welfare, at least some of the time. Leading figures in the positive political economy literature (e.g., Laffont and Tirole 1991, Dixit 1996) still think about designing optimal regulatory policies (e.g. Laffont and Tirole 1990, Dixit 1988). This contrast suggests these scholars may believe that policy makers, politicians and voters sometimes wish to act in the national interest. Some political scientists argue that many people are more public-spirited than public choice researchers usually assume, and that these people support policies they believe will further nationally worthwhile goals, rather than their own narrow selfinterests (Kinder and Kiewiet 1981; MacKuen, Erikson and Stimson 1992).

A large and fruitful scholarly discussion continues as to the relative importance of diverse self-interests and public-spirited goals in explaining political outcomes. But relatively little attention has been paid to the potential role played by the diversity of descriptive beliefs about the workings of the economic world. Blendon et al. (1997) note that "only $28 \%$ [of the US public] think price increases are mainly due to the laws of supply and demand," and "nearly three-fourths of the public believed that the increase in gasoline prices [in 1996] was due more to the oil companies trying to increase profits than to supply and demand" while $85 \%$ of economists 
believed supply and demand explained the price increase. Even in seemingly simple cases where citizens largely agree on national goals (for instance poverty reduction or national security), they often seem to differ sharply over which policies will in fact achieve those goals.

Romer (2003) recently gave a theoretical account of how diversity of descriptive beliefs can result in inefficient policy outcomes even when interests do not vary, and Matsusaka (1995) offered a similarly-based model of voter turnout. Modern choice theories decompose subjective preferences into a combination of values and beliefs. Obviously some differences among citizens' policy preferences may derive as much from differences in descriptive beliefs about the workings of the world as from differences in interests or goals. Moreover, cognitive approaches to political conflict resolution focussed on beliefs about alternatives sometimes succeed even when interests differ (Hammond and Adelman 1976). Again, the Diamond and Mirlees (1971) framework could only describe actual policy if there was widespread agreement in the electorate as to how economic institutions and government interventions into them actually work. Therefore, part of the divergence of policy from policy advice may stem from diversity of voter opinions as to how the economic world actually works.

The recurring significance of "ideology" in empirical studies of political preferences (most recently, see Blinder and Krueger 2004) and outcomes provides one reason to take this idea seriously. Political scientists have found that citizens' and politicians' views about policy mostly fall along an unidimensional axis corresponding to a "left-right" spectrum of political ideologies (Poole and Rosenthal 1991). Rubin's (2001) survey concludes that while electoral constraints based on voter interests limit politicians' behavior, "factors measuring ideology have large power in explaining congressional voting." While ideology could simply be the product of interests or a self-serving reflection of them, theories of bounded rationality provide a different 
explanation for the relationship between ideology and political preferences: people with imperfect information and limited computational abilities may use their ideology to evaluate new information. This could happen in several ways. Perhaps people use their ideology to evaluate descriptive claims when evidence is scanty or difficult to evaluate. Or, people may think that descriptive claims made by others with ideologies different from their own are ideologically motivated, and hence may discount them. DeMarzo et al. (2003) create a formal model in which reports with varying amounts of new information provided via a social network influence the opinions of boundedly rational individuals. Individual opinions then converge towards some unidimensional axis, and political ideology is a natural interpretation of this axis. Thus the relationship between ideology and descriptive beliefs may well be a two-way street: as people get new data influencing their descriptive beliefs about the workings of the economic world, they update their ideology. Romer (2003) concludes his theoretical analysis of the role played by diversity of beliefs in political economy as follows:

[T] he research program suggested by this paper is that of bringing ideology back into the analysis of politics...Ideological debate and rhetoric are prominent features of politics. There may be a great deal to be learned if we do not presume that such rhetoric is just a mask for individuals' well-informed pursuit of their self-interest, but instead consider the possibility that it often reflects individuals' beliefs, and that these beliefs often influence their actions.

Using a combination of experimental economics and survey methods, we find an interesting and sometimes surprising relationship between ideology and beliefs about the empirical adequacy of supply and demand theory. Our results suggest ideology is indeed related to descriptive beliefs about how markets actually work. We also show that other socioeconomic and personality characteristics potentially correlated with ideology do not explain away its relationship to descriptive beliefs. For instance, despite our efforts to maintain the anonymity and privacy of our subjects' responses, we find significant evidence of "socially desirable 
responding" in subjects' prior beliefs; and we also find that "trust of authority" is correlated with ideology as we expected. However, neither trust of authority, nor socially desirable responding, nor any demographic or socioeconomic characteristic of subjects or the families they grew up in (that we measured) explain away the relationship between ideology and prior beliefs about the descriptive accuracy of supply and demand theory. However, women in our second study are more skeptical about supply and demand theory than their male counterparts, even controlling for ideology. Our subjects' posterior beliefs respond strongly, and in a minimally reasonable way, to the experimental evidence they observed during their class session. Therefore, we think subjects were engaged with the experimental demonstration and took our survey and belief elicitations seriously. Finally, we find no evidence that ideology and beliefs are correlated merely because they are self-serving rationalizations. We believe that our results can be seen as support for Romer's (2003) suggested research program.

\section{Study Designs, Procedures, Measurements and Variables}

The basic plan of these studies is simple. Take a group of people who were exposed to economic theory X. Survey their characteristics, and measure their "economic ideology" and other possibly relevant personality traits. Then give instructions for an experiment designed to test theory X; recruit volunteers from the group to act as subjects in the experiment; and have the remainder observe the experiment. Allow the volunteers to practice while others watch, so the experimental procedures are salient to all. Then elicit prior beliefs from all in the group as to how well theory $\mathrm{X}$ will predict outcomes. Conduct the experiment, review the results and compare them to the predictions of theory $\mathrm{X}$. Then elicit posterior beliefs as to how well theory $\mathrm{X}$ will predict in a future experiment using the same design, but with a new group of people. 
We report results of two separate studies. The first was conducted in the summer of 2000 . On the basis of its results, small follow-up studies and interesting suggestions and criticisms, we conducted a second study in the summers of 2002 and 2003. Subjects for both studies were students enrolled in introductory summer term economics classes at the University of Houston. ${ }^{1}$ These courses begin with an introduction to the supply and demand (or CE, for competitive equilibrium) theory of market behavior. Sessions took place in regularly scheduled classes. We arranged with instructors to visit classes shortly after they had introduced CE theory to their classes. $^{2}$ We told each class that our primary mission was pedagogical— that most of the session would be devoted to an experiment used by instructors across the country as a normal part of economics classes like theirs (which is true). We also said session data would be used for research, but said nothing about our research questions.

The subsections below describe the procedures used for the two studies, the data collected and measurement of beliefs, ideology and personal traits. Some broad results of the first study, and its potential deficiencies, are also discussed here to motivate various changes in data collection and procedures incorporated into the second study.

\section{I.A. The initial surveys}

Subjects received a playing card, and were instructed to use their card as their "name" when filling in responses to the initial survey and other response forms throughout the session. We told subjects this protected their privacy while enabling us to link up their responses later for research purposes. In both experiments, subjects then received an initial survey which included

\footnotetext{
${ }^{1}$ University of Houston students are unusually diverse, exhibiting relatively large variance in their characteristics, which makes them a relatively interesting student body for our purposes. In 2004, U.S. News and World Report ranked it as the second-most diverse Ph.D.-granting university in the United States. See also Tables 1-A and 1-B.
} 
standard demographic and economic items such as age, sex, race, ethnicity and measures of socioeconomic status, as well as other items we thought might explain differences in subjects' ideological leanings, such as whether their families own stock, include union members or have suffered from various adverse events in the past ten years. In the second study, some questions that were poor predictors of both beliefs and ideology in the first study were dropped and other questions were added. In particular, we gathered more information on each subject's family background to get more variables that might correlate with subjects' ideology but would be arguably exogenous to the subjects (for instance, their parents' education, ideology and religion). Tables 1-A and 1-B summarize all of the variables we use. ${ }^{3}$

The survey measured ideological leanings in two ways. First, subjects provided a selfreport of "natural language ideology" by placing themselves on a seven-point scale from very liberal (coded as 1) to very conservative (coded as 7). Such scales have appeared in the National Election Surveys and political scientists use them for research. We call this variable OWNID_SR (“Own Ideology—Self-Reported"). Subjects could also choose "Don't know or haven't thought much about this." We code these responses as 4 , the same code as for the response "Moderate, middle of the road," but also set a dummy variable we call APATHY equal to 1 for these subjects, because political scientists find such respondents differ in their political behavior from those who identify themselves as moderate or middle of the road.

Subjects in the first study also responded to eleven statements about general economic policy issues taken from National Opinion Research Center surveys. Subjects could agree or disagree with each of these statements on a five-point scale, coded from 1 ("strongly agree") to 5

\footnotetext{
${ }^{2}$ Although we use the first-person plural, "the experimenter" was always the second author. This was deliberately done to avoid the possibility of "experimenter effects" that vary with subject or classroom characteristics.

${ }^{3}$ We also collected information on each subject's own personal history, such as their job experiences, schooling status, and so forth. However, we have decided to use only exogenous characteristics (those that are not the result of
} 
("strongly disagree"). Responses to five of the eleven items combine to create an "economic ideology" scale with good psychometric properties (Present author(s) 2002). ${ }^{4}$ Due to an error, only four of these five items appeared in the survey used for the second study. To maintain comparability across the two studies, we use just those four items:

- The way most companies work, the only thing management cares about is profits, regardless of what workers want or need.

- What one gets in life hardly depends at all on one's own efforts, but rather on the economic situation, job opportunities, union agreements and the social services provided by the government.

- Corporations should pay more of their profits to workers and less to shareholders.

- Workers need strong trade unions to protect their interests.

OWNID_MQ (“Own Ideology—Multiple Questions”) is the sum of subjects' coded responses to these items and we refer to it as "economic ideology." While this measure can range from 4 (most liberal) to 20 (most conservative), no subject reached either extreme.

OWNID_MQ was a strong predictor of subjects' beliefs in the first study. In the second study, we added survey items to address two alternative explanations for this fact. First, professors in the classroom are authority figures, and ideology may correlate with "trust of authority." ${ }^{5}$ Subject beliefs might be primarily determined by their trust of authority (the "authority" here being their instructor) and their ideology might simply be an instrument for that trust. In follow-up work between the two studies, as well as in the second study itself, we

the subjects' own choices) in our data analysis. Obviously this includes age, sex, race and ethnicity. However, it also includes information about each subject's family background.

${ }^{4}$ Most of the items used to construct the economic ideology scale have more to do with whether subjects identify more closely with the interests and views of managers than those of workers, than whether subjects accept the views of classic economic conservatives. For example, many economists would adopt the first item as the starting point for economic analysis of the firm; Milton Friedman even argues that corporations should only care about profits. Nevertheless, a subject agreeing with the first item, that most companies' managements only care about profit, would be regarded as more liberal; and indeed all four of these items show substantial positive intercorrelations. 
examined responses to eight items meant to measure trust of authority, and found three items whose coded responses combine to create a scale with acceptable psychometric properties. A five-point scale for responses was also used for these items, coded from 1 ("strongly agree") to 5 ("strongly disagree"). We used these three items in the second study's survey:

- Most "authorities" are just people with some credentials like a degree or a license, and that doesn't mean that they know anything special.

- Most of what professors teach is fine in theory, but the real world is actually different from what most professors teach.

- Social scientists and psychologists don't know any more about real human behavior than what everyone knows from common sense.

We call the sum of the coded responses to these three items TRUST (of authority). Less than 1\% of the second study subjects reach the minimum possible value (3, least trusting) and none reach the maximum possible value (15, most trusting). As we expected, OWNID_MQ and TRUST are significantly and positively correlated in the second study (Pearson correlation $=0.278$ and Kendall's rank correlation $=0.212$, both significant at $p<0.0001)$.

Heterogeneity in the propensity for "socially desirable responding" may also create a spurious relationship between stated beliefs and stated ideology. If a subject believes that certain responses are "desired" by some audience, and if she is (at least partially) motivated by a desire to please that audience, we then say she has a propensity for socially desirable responding (SDR). Intuitively, people with a propensity for SDR tend to "tell lies" they believe will please their audience. ${ }^{6}$ In our context, we are the subject's audience. As we are economists, subjects may believe that they please us by indicating that they believe in economic theory. As economists also have a reputation for being relatively conservative scholars, subjects may

\footnotetext{
${ }^{5}$ We both recall that in our youth, it was primarily the liberals who wore the "Question Authority" buttons.
} 
believe they will please us by identifying themselves as conservatives. If subjects with higher propensities for SDR are more likely to do both things "to please us" then differing propensities for SDR could generate a spurious relationship between stated beliefs and stated ideology.

Survey conditions that guarantee a high degree of anonymity can mute or even eliminate the propensity for SDR (Paulhus 1984). We took numerous precautions to enhance response anonymity and told subjects about these precautions verbally and in printed reminders in the surveys. Nevertheless, in classroom environments SDR may persist despite these precautions: essentially survey respondents need full privacy before SDR reliably disappears. Therefore, we measured the "impression management" (IM) component of SDR, which Paulhus (1991) says is particularly sensitive to public/private response conditions. An IM scale is meant to pick up conscious manipulation of responses by subjects. Paulhus' IM scale uses twenty items; to keep our survey short we selected just ten of these. Each item is a statement that the subject either does or does not exhibit some nearly universal but socially undesirable behavior. Subjects respond on a five-point scale from "very true" to "not true at all." Here are the ten items:

- I sometimes tell lies if I have to.

- I never swear.

- I have some pretty awful habits.
- I never cover up my mistakes.

- I sometimes drive faster than the speed limit.

- I have never dropped litter on the street.

- When I hear people talking privately, I avoid listening.

- I have done things that I don't tell other people about.

-I don't gossip about other people's business.

- I have said something bad about a friend behind his or her back.

\footnotetext{
${ }^{6}$ In the psychometric literature, some SDR scales are actually called "lie scales."
} 
To construct a close analogue of Paulhus' scale we assign one point for responses that are the most extreme denial of the socially undesirable behavior (e.g., responding "not true at all" to "I sometimes tell lies if I have to", or responding "very true" to "I never swear") and a half point for responses that are the second-most extreme denial of such behavior. ${ }^{7}$ We call the sum of these assigned points across the ten responses LIES. In the second study, about $11 \%$ of subjects deny none of the ten behaviors, and thus achieve the minimum possible value (0) on this measure. The highest score we observe is 7 , well below the maximum possible value (10).

\section{I.B. Experimental protocol instructions}

After the surveys were completed and collected, we announced that twelve subjects would be asked to volunteer as buyers and sellers in a Double Auction (DA) trading experiment. We then told the class that CE theory, which they recently studied in their class, could be used to predict what would happen in that experiment. Specifically, the subjects were reminded that $\mathrm{CE}$ theory predicts trading prices, the number of units traded, and total surplus (phrased "the combined earnings of all traders"). The experimenter said that he had used CE theory to predict the results of the experiment and had sealed his predictions in an envelope which was then produced and handed to a subject for safekeeping until after the last trading period.

DA trading experiments are perhaps the best-known market experiments and are widely used as teaching tools in introductory economics courses. For a detailed description of procedures, and sample instructions and trading records for the subjects, see Davis and Holt (1993). The oral DA market resembles organized "open outcry" markets such as the futures and commodity markets of Chicago. Any buyer or seller may, at any time, make an offer to buy or

\footnotetext{
${ }^{7}$ We say "close analogue" because Paulhus uses a seven-point response format and assigns 1 point for either the most extreme or second-most extreme denial. We wanted a consistent five-point response format across all survey
} 
sell to the other side of the market; and contracts occur when any buyer or seller accepts such offers from the other side. The rules are often supplemented by an offer improvement rule. We use the so-called "NYSE rule" which requires new offers to improve on outstanding offers from the viewpoint of the other side of the market. In preparation for the DA market experiment, all subjects were asked to follow along as the experimenter described how the volunteers, in randomly assigned roles as buyers or sellers, could make money buying and selling units of an imaginary good in the coming market. The experimenter used overhead projector slides to illustrate how volunteers could make money when they made a sale (if they were sellers) or made a purchase (if they were buyers) at some contract price. The rules of the DA market, including how pairs of volunteers could agree on a contract price, were then explained similarly.

Twelve volunteers were then recruited, randomly sorted to roles as buyers or sellers, and given paper trading forms to record their trades. Each buyer's form showed her own unit value, and each seller's form showed his own unit cost. Each subject could buy or sell at most one unit per trading period. The trading forms provided space to record contract prices and to calculate any resulting profits for one practice round, during which no money would be at stake, and for five subsequent trading rounds for actual money earnings. Then the practice round of the experiment was run with the twelve volunteer traders while the other subjects observed. Traders then calculated what their earnings would have been if the practice round had been for money, and the experimenter checked these for accuracy and understanding. 


\section{I.C. Elicitation of prior and posterior beliefs}

Immediately after the practice round, an expectations response form was handed out to all subjects in the room-traders and observers alike. In the first study, subjects judged how accurately they thought CE theory would predict (1) the average trading price, (2) the number of units traded, and (3) the combined earnings of the buyers and sellers (total surplus) in the final trading period. We reminded subjects about the envelope containing the $\mathrm{CE}$ predictions regarding these three things and then asked them to make their judgments on four-point scales. Here, for instance, is the item eliciting these "prior beliefs" about price predictions:

- How accurately do you think competitive market theory will predict the average trading price in the last trading period?

_ Very accurately

_ Somewhat accurately

_ Somewhat inaccurately

— Very inaccurately

Subjects' responses were coded from 4 (very accurately) to 1 (very inaccurately). The sum of these coded expectations, ranging from a high of 12 to a low of 6 among subjects in the first study, is one of our chief dependent variables, which we call ANTESUM (the sum of ex-ante judgments). We call the separately coded responses to beliefs about the accuracy of price, quantity and efficiency predictions ANTE_P, ANTE_Q and ANTE_E, respectively.

The response forms were collected and five trading periods (for real earnings) commenced. After the fifth and final period, the subject holding the predictions envelope was asked to open it and read the predictions one at a time. The experimenter compared each prediction to the data (still on the board) from the fifth and final round, noting explicitly whether the prediction had been correct or not. After this, a second, somewhat different expectations response form was distributed to all subjects in the first study. This instrument elicited the same 
information as the previous response form, using the same response categories and virtually the same wording, except in a retrospective format. Here, for example, is the price item:

- Based on your observations of the double auction experiment, how accurately do you think competitive market theory predicted average trading prices in the last period?

- Very accurately
- Somewhat accurately
— Somewhat inaccurately
— Very inaccurately

Responses were coded in the same way as for prior beliefs. The sum of these coded responses, ranging from a high of 12 to a low of 6 in the first study sample, is also one of our chief dependent variables, which we call POSTSUM (the sum of ex-post judgments). POST_P, POST_Q and POST_E are the separately coded responses for the price, quantity and efficiency predictions respectively.

Both judgments about the accuracy of CE theory (ex-ante and ex-post) were significantly and positively related to OWNID_MQ in the first study. In retrospect, we thought the wording of these items and choice of response categories could be improved. In particular, couching the judgment task in terms of accuracy may have been a poor choice. First, ideology could be related to the way in which people use the word "accurate," rather than beliefs about a theory's descriptive adequacy. More importantly, although past accuracy is certainly a part of any sensible judgment of future predictive performance, the two are not exactly the same; a Bayesian for instance would combine observed evidence with priors in forming her posterior judgment.

Our use of qualitative verbal response categories for belief elicitation items is not standard experimental economics practice, where numerical likelihood reports and incentivized proper scoring rules have been the normal method. However, a substantial literature in statistics and psychology exists on the use of verbal expressions of likelihood (Mosteller and Youtz 1990). 
It is known that people prefer to express their own probability judgments verbally rather than numerically, and that these judgments show a high degree of internal consistency. While both methods have their own small advantages, authorities conclude that for many purposes there is little to systematically recommend one over the other (Wallsten, Budescu and Zwick 1993). Incentivized judgments using proper scoring rules can somewhat reduce overconfidence in judgment and increase calibration (Wright and Aboul-Ezz 1989), but not in a big way; and econometric methods such as ordered logits can use the rankings implicit in verbal expressions of likelihood. Finally, some research suggests that incentivized numerical belief judgments may alter cognitive processes in ways that lead to artefactual results (Erev, Bornstein and Wallsten 1993; Croson 2000; Nelson 2003; Rutström and Wilcox 2003). Because most people prefer to use verbal expressions of likelihood; and because they do so in an ordinally consistent way without incentives, and econometric methods can use that ordinal information; and finally, because the tasks so constructed are easily and quickly explained to subjects; we see no strong reason to use either numerical and/or incentivized belief elicitation procedures in our particular context, and suspect there are some good reasons not to.

In our second study we made several changes in the belief elicitation items based on the literature on verbal likelihood judgments. First, we presented each prediction as a claim with CE theory's predictive accuracy embedded within the claim itself, and asked subjects to evaluate the likelihood that each claim will be correct. Second, we used five verbal categories formed on the basis of the stem "likely," which have been studied extensively, so that useful prior information exists about them (Mosteller and Youtz 1991). Here, for instance, are the instructions and the item used in the second study to elicit prior beliefs about the price prediction of CE theory. Responses are coded from 5 ("very likely") to 1 ("very unlikely"): 
We are about to do an experiment to see if the "competitive market" or "supply and demand" theory predicts the average trading price, the total number of units bought and sold, and the combined earnings of traders when trading takes place under the double auction rules we have discussed. Shortly, the volunteers from this class will actually trade for several trading periods under these rules. Please answer the following three questions about what you expect in the final trading period that these volunteers will trade in today. Please be as honest as you can. THIS IS NOT A TEST! We are interested in what YOU EXPECT of the predictive performance of the competitive market theory. Please be honest and forthright.

PREDICTION 1: "Supply and demand theory will, within a thirty cent range, predict the average trading price in the last trading period of today's experiment." (choose ONE):

$$
\begin{aligned}
& \text { Very Likely } \\
& \text { _ Likely } \\
& \text { _ Neither Likely nor Unlikely } \\
& \text { __ Unlikely } \\
& \text { _ Very Unlikely }
\end{aligned}
$$

For price predictions this presentation corrects a third weakness in the first study's belief elicitation. Most discrete supply and demand designs for market experiments CE theory either make a unique prediction for price or for quantity but not both. For the supply and demand design used in both studies, a 30-cent range of prices is consistent with competitive equilibrium. Because this could account for some of the difference between ex-ante and ex-post beliefs, stating the precise prediction accuracy of CE theory predicts better suits our purposes.

Finally, the retrospective format for ex-post beliefs in the first study could have been a poor choice. Asking how accurately a theory has performed is not clearly the same thing as asking whether the theory is expected to predict well in its next empirical test, for reasons we have already discussed. Therefore, we modified instructions for the ex-post belief elicitations of the second study to orient subjects toward beliefs about an imagined future experiment, rather than the one they had just observed, as shown here for the example of the price predictions of the theory. Responses to this item are coded from 1 ("very unlikely") to 5 ("very likely"): 
Please imagine now that exactly the same experiment is going to be done in a class similar to this one in a few days. Below, we would like you to say how likely you think it is that each of the predictions will be true in the fifth and final trading period the new class will see. Please be as honest as you can. THIS IS NOT A TEST! We are interested in what YOU EXPECT of the predictive performance of supply and demand theory. Please be honest and forthright, and make sure to make a judgment for each of the three predictions below.

PREDICTION 1: "Supply and demand theory will, within a thirty cent range, predict average trading prices in the last trading period of the imagined future experiment." (choose ONE):

Very Likely
Likely
Neither Likely nor Unlikely
_ Unlikely
_ Very Unlikely

As in the first study, ANTE_P, ANTE_Q and ANTE_E are the coded responses to the ex-ante price, quantity and efficiency belief items and POST_P, POST_Q and POST_E are the corresponding ex-post belief items. ANTESUM is again the sum of ex-ante responses and POSTSUM the sum of ex-post items. ${ }^{8}$

\section{Results}

\section{II.A. Reasonableness of elicited beliefs}

First, changes in belief elicitation procedures in the second study affected the internal properties of elicited beliefs. These effects follow sensible patterns. Table 2, for instance, tests whether pairwise differences in ex-ante belief measures differ within each study. In the first study, they do not: within-subject pairwise differences between ANTE_P, ANTE_Q and ANTE_E are essentially zero in the first study. In the second study, by contrast, ANTE_P is significantly greater than both ANTE_Q and ANTE_E, but ANTE_Q and ANTE_E do not differ themselves. This is sensible. In the first study the ex-ante belief items treat each prediction

\footnotetext{
${ }^{8}$ ANTESUM ranges from a low of 5 to a high of 15 in the second study sample. POSTSUM ranges from a low of 6 to a high of 15 in the second study sample.
} 
symmetrically: these items did not alert subjects to the fact that $\mathrm{CE}$ theory will predict a range of prices, but will predict unique values of quantity and efficiency. In the second study, by contrast, ex-ante belief items did alert subjects to this difference, and subjects responded with ex-ante beliefs concerning price predictions that are more optimistic than beliefs concerning the more precise predictions for quantity and efficiency.

Second, we check whether subjects responded to evidence in a minimally reasonable way. Table 3 suggests that they did. Four of the six classes in the first study (67 of those 128 subjects) observed one or more prediction errors in the final trading period; and two of the eleven classes in the second study observed errors for all three predictions ( 27 of those 216 subjects). Treating subjects who did and did not see prediction errors as independent samples within each study, Table 3 reviews one-tailed tests of the hypothesis that changes in beliefs (that is, differences between ex-post and ex-ante belief measures) were no larger among subjects who saw no prediction errors than among those who did. This hypothesis is almost always rejected, and the rejections are particularly strong in the second study. Therefore, changes in beliefs are broadly consistent with the evidence viewed.

The relationship between beliefs about how markets work and evidence has one somewhat curious feature. In the first study, though not in the second, there was variation in the number of prediction errors subjects observed among the 67 subjects who saw any prediction errors. Two classes observed just one prediction error (34 subjects saw only an efficiency prediction error) while two other classes observed two prediction errors (33 subjects saw an efficiency prediction error and either a price or quantity prediction error, but not both). As we show later in Table 5, which reports a fuller multivariate analysis of beliefs, neither ex-post beliefs nor changes in beliefs differ significantly between these two groups of subjects. 
This suggests that subjects evaluated the theory and all of its predictions as a whole, penalizing all predictions in their ex-post beliefs for any prediction error at all. However, extra prediction errors did not count much as extra evidence against the theory. Indeed subjects' belief changes exhibit a high degree of internal response consistency. For example, in the first study just $14 \%$ of subjects changed any two of their beliefs about price, quantity and efficiency predictions in opposite directions, and this percentage does not vary significantly with the evidence observed by subjects. In the second study this figure is only $10 \%$. In the context of CE theory makes some sense, as the three predictions are linked within the theory and certain errors have necessary linkages, and so are not independent events. For instance, a quantity prediction error necessarily implies an efficiency prediction error (given the supply and demand array we used for the experiments). We do not claim that subjects' belief updating was fully rational, but rather that subjects paid attention to the belief elicitation items, reacted to them in sensible and consistent ways, and responded to evidence in a minimally reasonable manner.

\section{II.B. Bivariate relationships between ideology and beliefs}

Table 4 shows nonparametric correlations using Kendall's $\tau$ between the two ideology measures and all belief measures (and changes in belief measures). The first two columns show results from the first study while the second two columns show results from the second study. The first and third columns show that there is essentially no relationship whatsoever between beliefs and OWNID_SR, the self-placements of our subjects in one of the categories from "very liberal" to "very conservative." That ideological self-placements are too blunt an instrument for this work is not surprising: these reflect a balance of attitudes towards many different things, such as abortion, which have little or nothing to do with economic ideology per se. Indeed, 
although the two ideology measures are significantly correlated in the expected direction, the size of the correlations by no means suggest that the two measures are identical (Kendall's $\tau=$ 0.2275 and 0.1563 in the first and second studies, both significant at $p<0.01$ ).

By contrast, the second and fourth columns indicate systematic relationships between beliefs and OWNID_MQ in both studies. Comparison of the second and fourth columns in the top four rows of Table 4 shows that the relationship between ex-ante belief measures and ideology is remarkably consistent across the two studies. However, the lower rows show that this is untrue for ex-post beliefs and thus is also untrue for changes in beliefs. The first study's "retrospective accuracy" frame for ex-post belief elicitation produces results just like those for ex-ante beliefs, which are also elicited with a "prospective accuracy" frame: both result in strong positive relationships between ideology and belief. But changes in beliefs and ideology are uncorrelated. This fits a Bayesian story in which ideology influences priors, and that influence passes into the posteriors, but the effect of evidence on the difference between the two is independent of ideology.

By contrast, the results of the second study do not lend themselves as easily to this Bayesian interpretation. There, both ex-ante and ex-post belief elicitations are framed in terms of the likelihood of the theory being correct in the immediate future. As explained earlier, we think this framing is better suited to our purposes. While ex-ante beliefs and ideology share a significant positive relationship, ex-post beliefs and ideology are uncorrelated. As a result, changes in beliefs are significantly negatively related to ideology. Conservatives start more optimistically, but end up with roughly the same beliefs as the liberals.

The "representativeness heuristic" for probability judgment may partly explain this result. In the absence of clear evidence, subjects must somehow form their priors, and in part may 
depend on their ideology to do so. But in the face of evidence, the subjects might ignore their priors and all end up with similar posterior beliefs regardless of the differences in their priors. Kahneman and Tversky (1972) argue that much the same thing happens to base rate information in the face of sample evidence. In their own experimental work, people who view the same evidence but different base rate information end up with largely the same posterior judgments. Recent evidence, however, suggests that this "base rate neglect" phenomenon is fragile (Koehler 1996), so our results so far might also simply mean that prior beliefs are weakly held, and hence easily overwhelmed by the direct and unambiguous evidence of the experiment. However, the multivariate analysis of posterior beliefs, to which we now turn, will yield a surprise.

\section{II.C. Multivariate analysis of beliefs}

Stated ideology and stated beliefs could be related through some third, confounding variable which determines both of them. For this reason, we measured "socially desirable responding" in the second study using the variable we call LIES. Ideology could also be correlated with other personal characteristics that determine beliefs, so that ideology simply acts as a proxy for these other characteristics. For this reason, we gathered many characteristics of subjects in both studies, and we measured "trust of authority" in the second study using the variable TRUST. We include all of these characteristics and measures in multivariate ordered logit models of beliefs. Since our question is whether the relationship between beliefs and ideology is robust to any of these things, the appropriate test is to include all of these things and ideology in a statistical model of beliefs, and see whether the significant relationship between ideology and beliefs observed in Table 4 vanishes in such models. In short, it does not. For these analyses, we confine our discussion to the aggregate belief measures ANTESUM and 
POSTSUM formed by summing coded beliefs concerning the three predictions of the theory, as well as the variable DELTASUM which is (ANTESUM-POSTSUM). Disaggregated results on the relationship between ideology and beliefs about each of the three predictions separately differ in the manner one would expect from the results in Table $4 .{ }^{9}$

Table 5 displays regression results for the first study. Here, the TRUST and LIES measures are unavailable. On the other hand, as noted earlier, there is systematic variation in the number of prediction errors observed by subjects who saw any errors (unlike in the second study). The second and third rows of the table show that although the observation of at least one prediction error decreases ex-post belief in the theory and hence changes in beliefs. However, observing a second prediction error has no significant marginal effect. Women's ex-ante beliefs are significantly more skeptical than those of men, but their ex-post beliefs are actually slightly (though not significantly) more optimistic than those of men. That women change their beliefs significantly more than men reflects these two effects. Subjects in the first study who grew up with a union member in their household have more skeptical ex-post beliefs than others. This result was not replicated in the second study (see Table 6) so we discount it. Aside from these effects, only the ideology measure OWNID_MQ is significantly related to market beliefs.

In the first study, several survey items meant to be proxies for interests were disappointing predictors of both ideology and beliefs. The item "Does your family own any stocks?" was one such example. The question concerning family income categories was similarly

\footnotetext{
${ }^{9}$ Summing responses across belief items—or for that matter, across the ideology, trust and lie items—presumes that those responses have interval scale meaning. Strictly speaking, this is false since these are all ordinal responses. Therefore, we have also performed all of our analyses using "Rasch scales" of the economic ideology, trust of authority and lie scales as well as for ANTESUM and POSTSUM. Rasch analysis constructs a latent variable model of ordinal responses to test items, including subject-specific and item-specific variance components in the latent variable. The Rasch scale values for subjects are essentially the estimated subject-specific components of the latent variable; see Baker (1992) for a detailed exposition. Qualitative results using an OLS analysis of Rasch belief scales were almost identical to the results we present here, using our ordered logit analysis of the scales created by simply summing item responses. Details are available from the authors.
} 
disappointing. Perhaps many subjects have only a vague idea of their parents' income, creating measurement error. So we dropped these questions and added three other questions to the second study's survey. One asked how many motor vehicles (including recreational vehicles and motorcycles) the subject's family owned, and another asked how many persons were in the subject's household (HHSIZE), in the subject's last year of high school. We call the ratio of these two variables CARPHEAD ("cars per head"). We hoped that this measure, based on two things subjects were likely to know well, would proxy family socioeconomic status and hence interests. We also asked whether the primary income earner in the subject's household had ever received any form of public assistance. ${ }^{10}$ If the subject said they had, the dummy variable HHWELF equals one. HHWELF, HHSIZE and CARPHEAD are all included in the models of beliefs elicited in the second study (HHSIZE is included to guard against the possibility that the significance of CARPHEAD is a spurious result of its denominator HHSIZE).

We also collected the zip code where a subject's family lived in the subject's last year of high school and linked this with 2000 U.S. census data. We use four variables meant to measure economic circumstances and inequality in these neighborhoods: the percentage of households receiving public assistance (PCTWELF), and the natural logarithms of first quartile (LQ1HV), median (LMHV) and third quartile (LQ3HV) dollar values of owner-occupied housing in these zip code areas. We construct two measures of wealth inequality from these: "lower wealth inequality," defined as LWI = LMHV - LQ1HV, and "upper wealth inequality", defined as UWI $=\mathrm{LQ} 3 \mathrm{HV}-\mathrm{LMHV}$. We separate these two measures because there is evidence that people find differences between themselves and those who are better off to be more aversive than differences between themselves and those who are worse off (Fehr and Schmidt 1999). We include the

\footnotetext{
${ }^{10}$ The survey listed unemployment insurance, food stamps, federal or state disability payments, public housing or vouchers, Medicaid, Medicare or "any type of government income assistance."
} 
variables PCTWELF, LMHV, LWI and UWI in the multivariate models of beliefs elicited in the second study, and refer to them in tables as "economic features of family's zip code area."

We also asked subjects in the second study to report the ideology of their parents on the same qualitative scale used to elicit ideological self-placements. These are averaged to form the variable AVGPARID. ${ }^{11}$ This variable is set to 4 ("Moderate") for subjects who don't know the ideology of either parent, and a dummy variable PARAP is then set equal to one. Both of these variables are included in our analysis of beliefs in the second study. Finally, we also asked subjects about their parents' religion. ${ }^{12}$ The three most common religions (collectively more than $80 \%$ of subjects) were Catholic, Protestant and Buddhist. Dummy variables CATHFAM, PROTFAM and BUDDFAM represent these responses; these are also included in our models of beliefs in the second study, and are collectively referred to as "family religion" in Table 6.

Table 6 displays the results of the ordered logit analysis for the second study. The TRUST and LIES measures are available here and are also in the models. Although TRUST is estimated to have positive effects on both ex-ante and ex-post beliefs as expected, it is insignificant in both belief models as well as the model of changes in beliefs. Therefore, the significance of ideology is not attributable to trust of authority. The measure of socially desirable responding LIES, however, is indeed a significant predictor of ex-ante beliefs (and in the expected positive direction); but it does not predict ex-post beliefs or changes in beliefs with significance. Nor is there a significant bivariate relationship between LIES and OWNID_MQ (Kendall's $\tau=0.0308, \mathrm{p}=0.54$ ). We conclude that although socially desirable responding seems to play a role in subjects' ex ante beliefs, it plays no role in responses to ideology items. Thus,

\footnotetext{
${ }^{11}$ Of course, if students report the ideology of only one parent, or don't know the ideology of one parent, AVGPARID is simply set equal to the reported ideology of the parent they do know about.

${ }^{12}$ In the case where their parents were of two different religions, students were instructed to report the religion of the parent they believed held their religious views most strongly.
} 
the relationship between stated market beliefs and stated ideology is not a spurious result caused by similar socially desirable responding in both of them.

As in the first study, women's ex-ante beliefs are significantly more skeptical than men's, but unlike the first study, women's ex-post beliefs are also significantly more skeptical: these two effects offset so that changes in beliefs are unrelated to gender. Taken together, these results may mean that women find CE theory less believable than men do, but caution is in order as a man (the second author) conducted all the experimental demonstrations. While evidence suggests an instructor's gender has little measurable effect on female students (Jensen and Owen 2001) and while evidence from two-person games suggests differences between female and male players quickly disappear (Ortmann and Tichy 1999), gender could have an effect if people are more trusting of a same-sex stranger than a different-sex stranger. ${ }^{13}$

Unlike the first study, race and ethnicity have a significant effect on ex-post beliefs, with whites more optimistic and Asians less optimistic than others, who are almost all Hispanics. Furthermore, family religious background has a significant effect on ex-post beliefs. Those from Christian backgrounds have more skeptical ex-post beliefs, while those from Buddhist backgrounds have significantly more optimistic ex-post beliefs. ${ }^{14}$ The education level of the subject's most educated parent is also a significantly positive predictor of ex-post beliefs and changes in beliefs: if the most educated parent has at least a college degree, ex-post beliefs are more optimistic than otherwise. Subjects who grew up in relatively large households tend to have more skeptical ex-ante beliefs, but positively change their beliefs more than others. ${ }^{15}$

\footnotetext{
${ }^{13}$ The second author's own classes were never used, and all classes were introductory economics classes; therefore, the second author who conducted the experiments was always (relatively speaking) a stranger to the subjects.

${ }^{14}$ In the University of Houston student body, Buddhist background may largely be a proxy for children of the Vietnamese diaspora. The two primary Asian groups at the University are South Asians and Vietnamese. Thus with a dummy variable for Asians in the models, BUDDFAM may be largely the same thing as Vietnamese ethnicity.

${ }^{15}$ People who grew up in relatively large families experience more diversity of human behavior, and this may leave them relatively skeptical of the idea that any human behavior can be predicted with accuracy.
} 
Finally, we return to our primary reason for estimating the relationship between ideology and market beliefs. Including all of these other scales and demographic variables in the models does not erase the significance of ideology at all; in fact it is somewhat stronger, and in a surprising way. In Table 4, the bivariate correlations between ex-post beliefs and ideology are actually negative in the second study, though not significantly so. In the multivariate analysis displayed in Table 6, this negative effect becomes significant, and this reinforces the significantly negative effect of ideology on changes in beliefs as well. That is, relatively conservative subjects are relatively more optimistic in their ex-ante beliefs, but relatively more skeptical in their ex-post beliefs: their a priori beliefs about CE theory are more generous, but they seem to react so much less to positive evidence that they end up more skeptical than their more liberal classmates. ${ }^{16}$ Because of the inconsistency of this finding across the first and second studies, and because we certainly didn't expect this, we remain cautious about how ideology affects ex-post beliefs. Yet as we have made clear, we are more comfortable with the results of the second study because the belief elicitation items in the second study are better suited to our research questions. Perhaps relatively conservative subjects hold their priors much more strongly than their relatively liberal counterparts and, as a result, update their priors so much less that their ex post beliefs are actually less optimistic than their more liberal counterparts.

\section{II.D. Is ideology either epiphenomenal or endogenous?}

Are ideology and beliefs merely self-serving reflections of narrow self-interest? If they are, their positive relationship is spurious and perhaps behaviorally uninteresting. We call this the "epiphenomenon hypothesis." Certainly since Marx, if not before, many have suspected that

\footnotetext{
${ }^{16}$ This effect should not be misunderstood: When viewing positive evidence in favor of the theory, both liberal and conservative students update their beliefs positively. Conservative students simply update their beliefs much less.
} 
"where you stand depends on where you sit." Marx heaped scorn on the notion that either ideology or beliefs about economic reality are anything other than self-serving rationalizations. ${ }^{17}$ Under this view, both ideology and beliefs are determined solely by variables which are correlated with narrow self-interest. Our results already cause a problem for this position: the evidence our subjects viewed in their classroom experiment is undoubtedly uncorrelated with their narrow self-interests, yet evidence is the single strongest predictor of ex-post beliefs in Tables 5 and 6 . But we can sympathize with the view that subjects are just responding to the central phenomena of the experimental demonstration at that time. We acknowledge that seeing experimental evidence once may not create permanent changes in subjects' beliefs, and that even if it does, it may not affect the way they will behave as citizens.

Arguing a priori that any of our exogenous variables, other than evidence, obviously relate or do not relate to self-interest is impossible. Yet the epiphenomenon hypothesis suggests that the same variables that proxy self-interests-whatever they may be-should determine ideology and beliefs, and in the same way. Therefore we put models of both ex ante beliefs and ideology side-by-side, estimated using an identical set of exogenous explanatory variables, and ask whether variables with significant coefficients in these models are essentially similar. The epiphenomenon hypothesis seems more tenable if they are similar, less plausible if they are not. Table 7 shows the results. The two columns show estimated effects of a common vector of exogenous variables on ex-ante beliefs and ideology. No variable has a significant coefficient in both models. Wherever a variable coefficient is estimated to be significant in one of the models, it is invariably insignificant in the other, casting doubt on the epiphenomenon hypothesis.

\footnotetext{
${ }^{17}$ At least Marx did this in some of his moods. At other times, Marx argued that people can be "in thrall" to views contrary to their self-interest.
} 
Of course, with so many insignificant variables and the possibility of intercorrelations between them, similarities between the determinants of ideology and beliefs could be masked by the large number of variables used in the models of Table 7. To examine this, we use both the Aikaki and Bayes Information Criteria (AIC and BIC, respectively) to select a subset of these variables as the "best" model of ex-ante beliefs and ideology and compare the results in Table 8. The BIC tends to select a relatively "lean" model while the AIC tends to select a relatively "fat" model, and this is true for both ex-ante beliefs and ideology. The left columns of Table 8 show the resulting models of ex-ante beliefs, while the right-most columns show the resulting models of economic ideology. Table 8 makes it plain that there is no overlap between the sets of explanatory variables selected by these criteria for beliefs and ideology.

The epiphenomenon hypothesis is, of course, just a very specific version of the more general possibility that beliefs and ideology are mutually endogenous. If so, our use of ideology as an explanatory variable in the models of Tables 5 and 6 is invalid. The Durbin-Wu-Hausman test can be used to check whether endogeneity is an obvious problem (Davidson and MacKinnon 1993). The first step in performing this test is to estimate an OLS regression of OWNID_MQ on the largest possible set of strictly exogenous variables (all the variables shown in Table 6 except for TRUST and LIES, which might themselves be endogenous) and recover the estimated residuals from this model. In the second step, we estimate an ordered logit model of ex-ante beliefs on a strict subset of the explanatory variables used in the first step (this is required for identification) and on both OWNID_MQ and its residual from the first step. The Durbin-WuHausman test uses a Wald statistic to determine whether the residual is significant in this secondstep model. If it is not, then we cannot reject the hypothesis that OWNID_MQ is exogenous. 
When identification hinges on excluding potential explanatory variables, solid a priori reasoning is the only truly satisfactory exclusion criterion. Such reasoning is unconvincing here. In lieu of this, considering a large number of alternative exclusions is the next-best thing. Therefore, we consider whether the residual of economic ideology is significant in any model of ex-ante beliefs ranging in size from zero to eight explanatory variables, where the included explanatory variables at each model size were selected to maximize the likelihood function. ${ }^{18}$ The minimum p-value against the hypothesis that the residual of ideology is zero across these nine models is 0.39 (occurring in a model with four other regressors besides ideology and its residual-FEMALE, ASIAN, BUDDFAM and HHSIZE). Using evidence from the first study can also be helpful, since this adds out-of-sample evidence as to which other explanatory variables might plausibly belong in the model of ex-ante beliefs. This strategy identified three such extra explanatory variables, which were added to the nine existing models of ex-ante beliefs, resulting in a minimum p-value on the residual of economic ideology equal to 0.33 .

In sum, there is little evidence here that ideology is either epiphenomenal or endogenous. Still, ideology is not wholly independent of self-interest: in fact, the models of economic ideology in Tables 7 and 8 support this view, since white, relatively old people from relatively well-off backgrounds (as measured by our s.e.s. proxy CARPHEAD) are relatively conservative. Self-interest matters to economic and political behavior; we would be unsurprised to learn that it determines most political behavior. We only claim that our data are inconsistent with the idea that ideology and belief are both merely self-serving rationalizations. Finally, we think ideology and beliefs must be mutually endogenous in the long run. Over shorter time periods, we suspect

\footnotetext{
${ }^{18}$ After eight included variables, the log likelihood never increases by more than unity when another variable is added, and no new variables added ever remotely approaches any conventional level of significance. In order, the explanatory variables selected for the eight models are, in order of selection, FEMALE, HHSIZE, ASIAN, BUDDFAM, CARPHEAD, PARAP, AVGPARID and CALAMITY.
} 
that ideology, like party identification, is stable and relatively exogenous; and is therefore a relatively exogenous determinant (among others) of descriptive beliefs about the workings of the economic world in the short and medium term. Our results here support this view.

\section{Discussion and Conclusions}

Does ideology matter? The answer is clearly yes when it comes to what our subjects expect of economic theory's predictive ability. Ideology may be a useful heuristic for judging social and economic policies in the absence of good evidence, or when arguments are complex and difficult to understand. As the Bayesian tradition gives little guidance on where priors come from, it is difficult to quarrel with priors that are related to ideology—which they are, and in the expected direction, in both of our studies. The Bayesian viewpoint also suggests this should be passed through to posterior judgments. Our evidence concerning ideology is consistent with this Bayesian story in the first study, but less obviously so in the second study. Perhaps judgments reflect the representativeness heuristic. Alternatively, relatively conservative people may have relatively strong priors that are less responsive to new evidence, and it may be that this effect is strong enough to reverse the expected correlation between ideology and beliefs after viewing clear and unambiguous evidence.

In the second study, we test and discount several alternative explanations for the observed relationship between ideology and beliefs. First, ideology may simply proxy "trust of authority," and although our measure of this concept is correlated with ideology, as expected, only ideology is a significant predictor of beliefs in multivariate models that include both of them. Second, stated ideology and stated beliefs may both be the outcome of heterogeneous propensities for "socially desirable responding." The LIES measure of this propensity is significantly related to 
stated beliefs. However, it is unrelated to ideology, so both are significant predictors of ex-ante beliefs in models that include both of them. The third point is, in a sense, a different version of the second: ideology and beliefs might both be epiphenomenal by-products of something elsein this case self-interest. However, ideology and beliefs are predicted by wholly disjoint sets of exogenous explanatory variables—not a promising beginning for this explanation of their relationship. Finally, and most generally, ideology and beliefs are probably mutually endogenous, especially in the long run. This could cast doubt on the validity of our statistical analysis. However, a widely used exogeneity test (Durbin-Wu-Hausman) indicates no obvious problem with the assumption that ideology is exogenous in our short term setting.

For all of these reasons, we think it is reasonable to adopt a working hypothesis that ideology is relatively exogenous and influences beliefs about the workings of the economic and social worlds, at least over relatively short time periods. What psychological and social mechanisms govern this process then becomes the question. We see four possibilities.

First, ideology could be a mental summary of a long history of encounters with policy arguments and evidence; and because of that long history, it may have great evidential strength in the mind of judges when they encounter new theories or evidence that they judge to be similar to what they have encountered and considered in the past. In this case, the strength of the judge's own ideology and the degree to which the judge perceives the new argument or evidence to be "more of the same old stuff" that she has considered in the past would be relevant factors. ${ }^{19}$

A second similar possibility, but with slightly different and richer implications, is that ideology measures or reflects "affect" attached in a judge's memory to some broad category of economic issues and policies. "Affect" resembles a utility estimate based on experience—an

\footnotetext{
${ }^{19}$ To the extent that people fail to notice redundancy of arguments or information, a "persuasion bias" could of course result simply from the repetition of arguments or evidence (DeMarzo et al. 2003).
} 
amalgam of positive and negative emotional reactions over the experiential history of the judge. In our context, affect is particularly interesting because it connects value and belief judgmentsjust as utility is a combination of value and belief in the modern theory of decision under uncertainty. However, affect is not thought to be coded in memory as separate value and belief estimates, but rather as an overall experiential estimate. Because of this, judgments based on affect provide a path for experiences of value to alter future beliefs and vice versa. For instance, Slovic et al. (2002) describe a manipulation wherein subjects are given different information about the benefits of a technology such as nuclear power. Subjects told that the technology has relatively low benefits subsequently judge its risk to be relatively great, compared to subjects told that the benefits are relatively great, who subsequently judge the risk to be low. So if ideology is essentially political affect, a clear cognitive route of influence links ideology to descriptive beliefs. Some political scientists have long argued that affective predispositions can help explain citizen's political preferences (e.g., Sears et al. 1980).

A third possibility is that ideology matters because citizens must decide whom and how much to trust. Information used to form beliefs always has its source, and sources need evaluation. If we as economists are viewed as ideologically distinctive, which in our experience is common, subjects with different ideological positions may well view our experimental demonstration differently. ${ }^{20}$ More generally, messages with policy implications resemble cheap talk in games. If receivers think their interests and those of senders diverge; and if receivers believe ideology partly reflects interests; then the question of what to believe depends less on the receiver's ideology than it does on the receiver's perception of the difference between her own

\footnotetext{
${ }^{20}$ This possibility was not tested in our second study with our "trust of authority" measure: items comprising this measure are about generalized trust for academic authorities and other experts—not items about how willing students are to trust people with specified ideologies.
} 
ideology and that of the sender. The relevant literature on cheap talk in games could guide future investigations of this role of ideology (e.g., Krishna and Morgan 2001).

Fourth, ideological differences may lead people to search for, process and remember different information about markets. For instance, consulting one's memory about markets is a reasonable thing to do when evaluating CE theory's likely predictive success. However, if liberals primarily remember Enron and conservatives primarily remember microbanks' success in reducing poverty in South Asia, their evaluations will differ. This is an instance of a judgment phenomenon called "confirmation bias" (Camerer 1995).

Economists often have mixed success in persuading non-economists of their views. We find some groups in particular are systematically more skeptical of economic theory's usefulness than others. However, as the saying goes, seeing is believing. Our results suggest that economists can persuade others that their theories are useful if they can point to clear and unambiguous evidence, as evidence can cut through the thicket of ideological filters. Of course, this is not easy to do. Interpreting data from surveys and statistical agencies requires econometric sophistication. Experimental data can provide clear results, but how those results apply to the world outside of the lab is not clear to many policy makers or voters (not to mention some economists).

To close, we return to our original motivation. We do not doubt that differences in interests, selfish or unselfish, drive much of political differences over policy, taxes and spending in democracies. However, differences in descriptive beliefs may also play a part. Modern choice theories decompose subjective preferences into values and beliefs; both affect choices. People of good will sharing similar values can and often do differ vehemently over questions of how market mechanisms in fact work. Descriptive beliefs matter, and they differ across individuals. 
Ideology may be a powerful force in shaping beliefs. North (1990) argues that

"It is simply impossible to make sense out of history (or contemporary economies) without recognizing the central role that subjective preferences play in the context of formal institutional constraints that enable us to express our convictions at zero or very little cost. Ideas, organized ideologies, and even religious zealotry play major roles in shaping societies and economies." (p.44)

One need not believe that ideology shapes the interests, goals and norms of citizens in order to agree with North. If ideology affects people's views of how the world actually works, that alone will influence their subjective political preferences. We have provided initial evidence that ideological differences may well influence descriptive beliefs about economic institutions. 


\section{References}

Present authors. 2002. What students expect and what they see: Ideology, identity and the double auction classroom experiment. CERGE-EI Working Paper 194.

Baker, Frank B. 1992. Item Response Theory: Parameter Estimation Techniques. New York, N.Y.: Marcel Dekker Inc.

Blendon, Robert et al. 1997. Bridging the gap between the public's and economist's views of the economy. Journal of Economic Perspectives 11(3):105-118.

Blinder, Alan S. and Alan B. Krueger. 2004. What does the public know about economic policy, and how does it know it? Brookings Papers on Economic Activity 2004(1):327-87.

Camerer, Colin. 1995. Individual decision making. In J. Kagel and A. Roth, eds., Handbook of Experimental Economics. Princeton, N.J.: Princeton University Press.

Croson, Rachel. 2000. Thinking like a game theorist: factors affecting the frequency of equilibrium play. Journal of Economic Behavior and Organization 41(3):299-314.

Davidson, Russell, and James G. MacKinnon. 1993. Estimation and Inference in Econometrics. New York, N.Y.: Oxford University Press.

DeMarzo, Peter M., Dimitri Vayanos and Jeffrey Zwiebel. 2003. Persuasion bias, social influence, and unidimensional opinions. Quarterly Journal of Economics 118(3):909-968.

Diamond, Peter and James Mirlees. 1971. Optimal taxation and public production 1: production efficiency and 2: tax rules. American Economic Review 61:8-27, 261-78.

Dixit, Avinash. 1988. A general model of R \& D competition and policy. RAND Journal of Economics, Vol. 19, No. 3. (Autumn, 1988): 317-326.

1996. The Making of Economic Policy: A Transaction Cost Politics Perspective (Munich Lectures in Economics). Cambridge, Mass.: M.I.T. Press, 1996.

Downs, Anthony. 1957. An Economic Theory of Democracy. New York, N.Y.: Harper.

Davis, Doug, and Charles Holt. 1993. Experimental Economics. Princeton, N.J.: Princeton University Press.

Erev, Ido, Gary Bornstein and Thomas S. Wallsten. 1993. The negative effect of probability assessments on decision quality. Organizational Behavior and Human Decision Processes 55:78-94.

Estrella, A. 1998. A new measure of fit for equations with dichotomous dependent variables. Journal of Business and Economic Statistics 16:198-205. 
Fehr, Ernst and Schmidt, Klaus M. 1999. A theory of fairness, competition, and cooperation. Quarterly Journal of Economics 114:817-68.

Hammond, Kenneth R. and Leonard Adelman. 1976. Science, values and human judgment. Science 194:389-96.

Haveman, Robert H. 1976. Policy analysis and the Congress: an economist's view. PolicyAnalysis 2(2): 235-50.

Jensen, Elizabeth J. and Ann L. Owen. 2001. Pedagogy, gender, and interest in economics. Journal of Economic Education 32(4): 323-343.

Kahneman, Daniel and Amos Tversky. 1972. Subjective probability: a judgment of representativeness. Cognitive Psychology 3:430-54.

Kinder, Donald R. and D. Roderick Kiewiet. 1981. Sociotropic politics. British Journal of Political Science 11:129-61.

Koehler, Johnathan J. 1996. The base rate fallacy reconsidered: Descriptive, normative and methodological challenges. Behavioral and Brain Sciences 19:1-53.

Krishna, Vijay and John Morgan. 2001. A model of expertise. Quarterly Journal of Economics 116:747-775.

Laffont, Jean-Jacques and Jean Tirole. 1990. Optimal bypass and cream skimming. American Economic Review 80:1042-61.

. 1991. The politics of government decision-making: a theory of regulatory capture. Quarterly Journal of Economics 106:1089-1127.

MacKuen, Michael B., Robert S. Erikson and James A. Stimson. 1992. Peasants or bankers? The American electorate and the U.S. economy. American Political Science Review 78:372-91.

Matsusaka, John G. 1995. Explaining voter turnout patterns: an information theory. Public Choice 84:91-117.

Mosteller, Frederick and Cleo Youtz. 1990. Quantifying probabilistic expressions. Statistical Science 5:2-12.

Nelson, William Robert. 2003. Dictators, expectations, and the order of decisions: an experiment. State University of New York at Buffalo, School of Management Working Paper.

North, Douglass C. 1990. Institutions, Institutional Change and Economic Performance. Cambridge, U.K.: Cambridge University Press. 
Ortmann, Andreas and Lisa K. Tichy. 1999. Gender differences in the laboratory: evidence from prisoners' dilemma games. Journal of Economic Behavior and Organization 39:327-339.

Paulhus, Delroy L. 1984. Two-component models of socially desirable responding. Journal of Personality and Social Psychology 46:598-609.

1991. Measurement and control of response bias. In J. P. Robinson et al., eds., Measures of Personality and Social Psychological Attitudes, pp. 17-60. London and San Diego: Academic Press.

Romer, David. 2003. Misconceptions and political outcomes. Economic Journal 113:1-20.

Rubin, Paul E. 2001. Ideology. In William F. Shughart II and Laura Razzolini, eds., Elgar Companion to Public Choice, 328-336. Cheltenham, UK: Edward Elgar Publishing.

Rutström, E. Elizabet and Nathaniel T. Wilcox. 2003. Learning and belief elicitation: observer effects. University of Houston, Department of Economics Working Paper.

Sears, David O., Richard R. Lau, Tom R. Tyler and Harris M. Allen, Jr. 1980. Self-interest vs. symbolic politics in policy attitudes and presidential voting. American Political Science Review 74:670-684.

Slovic, Paul, M. Finucane, E. Peters and D. G. MacGregor. 2002. The affect heuristic. In T. D. Gilovich, D. W. Griffin and D. Kahneman, eds., Heuristics and Biases: The Psychology of Intuitive Judgment. Cambridge, U.K.: Cambridge University Press.

Stigler, George J. 1965. The economist and the state. American Economic Review 55:1-18.

1971. The theory of economic regulation. Bell Journal of Economics and Management Science 2:3-21.

Wallsten, Thomas S., David V. Budescu and Rami Zwick. 1993. Comparing the calibration and coherence of numerical and verbal probability judgments. Management Science 39:176-90.

Winston, Clifford. 1993. Economic deregulation: days of reckoning for microeconomists. Journal of Economic Literature 31:1263-1289.

Wright, W. and M. Aboul-Ezz. 1989. Effects of extrinsic incentives on the quality of frequency assessments. Organizational Behavior and Human Decision Processes 41:143-52. 
Table 1-A. Explanatory Variables Used in the First Study

\begin{tabular}{|c|c|c|c|c|c|c|c|c|c|}
\hline \multicolumn{10}{|c|}{ Mean, Standard deviation and centiles of noncategorical explanatory variables in the first study $(\mathrm{N}=128)$} \\
\hline & \multicolumn{2}{|c|}{\begin{tabular}{|c|} 
mean \\
\end{tabular}} & $\begin{array}{l}\text { standard } \\
\text { deviation }\end{array}$ & \multicolumn{2}{|c|}{$\begin{array}{c}10 \text { th } \\
\text { centile }\end{array}$} & \begin{tabular}{|c|}
25 th \\
centile
\end{tabular} & \begin{tabular}{l|l} 
50th & \\
centile
\end{tabular} & \begin{tabular}{c|}
75 th \\
centile
\end{tabular} & $\begin{array}{l}\text { 90th } \\
\text { centile }\end{array}$ \\
\hline OWNID_MQ ${ }^{\mathrm{a}}$ & 12.0 & \multicolumn{2}{|c|}{2.79} & 8 & \multicolumn{2}{|c|}{10} & 12 & 14 & 15 \\
\hline AGE & 23.1 & \multicolumn{2}{|c|}{4.66} & 19 & \multicolumn{2}{|c|}{20} & 21 & 25 & 30 \\
\hline CALAMITY $^{\mathrm{d}}$ & 1.25 & \multicolumn{2}{|c|}{1.30} & 0 & \multicolumn{2}{|c|}{0} & 1 & 2 & 3 \\
\hline \multicolumn{10}{|c|}{ Distributions of categorical explanatory variables used in first study } \\
\hline \multirow[t]{2}{*}{ OWNID_SR ${ }^{\mathrm{b}}$} & $\begin{array}{c}\text { Very } \\
\text { Liberal } \\
(=1)\end{array}$ & $\begin{array}{l}\text { Liberal } \\
(=2)\end{array}$ & \multicolumn{2}{|c|}{$\begin{array}{c}\text { Some } \\
\text { Liberal } \\
(=3)\end{array}$} & $\begin{array}{l}\text { Moderate } \\
\quad(=4)\end{array}$ & $\begin{array}{c}\text { Some } \\
\text { Conserv } \\
(=5)\end{array}$ & $\begin{array}{c}\text { Conserv } \\
(=6)\end{array}$ & $\begin{array}{c}\text { Very } \\
\text { Conserv } \\
(=7)\end{array}$ & $\begin{array}{c}\text { Don't } \\
\text { Know }^{\mathrm{c}} \\
(=4)\end{array}$ \\
\hline & $1.6 \%$ & $10.2 \%$ & & & $27.3 \%$ & & $14.1 \%$ & $4.7 \%$ & $11.7 \%$ \\
\hline Female & & FEI & $\overline{\mathrm{ALE}}$ & & & & If $=0$ & Male & \\
\hline & & & $8 \%$ & & & & 49. & $2 \%$ & \\
\hline $\begin{array}{l}\text { Race and } \\
\text { Ethnicity }\end{array}$ & WHIT & $E=1$ & & BLAC & $\mathrm{K}=1$ & & $\mathrm{~N}=1$ & $\begin{array}{l}\text { If all = } \\
\text { (mostly }\end{array}$ & $\begin{array}{l}\text { others } \\
\text { ispanic) }\end{array}$ \\
\hline (3 Dummies) & 38. & & & 18. & $0 \%$ & & & & \\
\hline $\begin{array}{l}\text { Family } \\
\text { Income }\end{array}$ & $\begin{array}{r}\mathrm{INC} 1= \\
(22 \mathrm{k} \text { to }\end{array}$ & & $\begin{array}{r}\text { IN } \\
(50 k\end{array}$ & $\begin{array}{l}=1 \\
75 \mathrm{k})\end{array}$ & $\begin{array}{r}\text { INC } \\
(75 \mathrm{k} \mathrm{t}\end{array}$ & $\begin{array}{l}=1 \\
100 \mathrm{k})\end{array}$ & $\begin{array}{r}\text { INC4 = 1 } \\
(>100 \mathrm{k})\end{array}$ & & $\begin{array}{l}11 \mathrm{l}=0, \\
22 \mathrm{k}\end{array}$ \\
\hline (4 Dummies) & $26.6^{\circ}$ & & & & & & $25.8 \%$ & & $5.4 \%$ \\
\hline $\begin{array}{c}\text { Max of Parents' } \\
\text { Education }\end{array}$ & $\begin{array}{l}\text { PARHS } \\
\text { (at least }\end{array}$ & $\begin{array}{l}\mathrm{CH}=1 \\
\mathrm{hs} \text { deg) }\end{array}$ & & $\begin{array}{l}\text { PARCC } \\
\text { east 4- }\end{array}$ & $\begin{array}{l}\text { OLL }=1 \\
\text { yr coll deg) }\end{array}$ & $\begin{array}{l}\text { PAR } \\
\text { (gra }\end{array}$ & $\begin{array}{l}\text { AD = 1 } \\
\text { te deg) }\end{array}$ & $\begin{array}{l}\text { If all }= \\
\text { (almost }\end{array}$ & $\begin{array}{l}\text {, other } \\
\text { ll no hs) }\end{array}$ \\
\hline (3 Dummies) & 89. & & & 53. & $1 \%$ & & & & \\
\hline Public High & & PUI & $\mathrm{SCH}$ & & & & 0, parochial & , private or $\mathrm{h}$ & \\
\hline School & & & $9.1 \%$ & & & & 10 & $9 \%$ & \\
\hline Union Member & & $\mathrm{HHL}$ & IION & & & & , no union & member in $\mathrm{f}_{\mathrm{c}}$ & nily \\
\hline in Family & & & $2.5 \%$ & & & & 87 & $5 \%$ & \\
\hline Family Owns & & $\mathrm{HH}$ & SET & & & & 0, no stock & s held by far & \\
\hline Stocks & & & $7 \%$ & & & & & $3 \%$ & \\
\hline
\end{tabular}

${ }^{a}$ OWNID_MQ: Own economic ideology measure, based on four item responses (see text)

${ }^{\mathrm{b}}$ OWNID_SR: Own ideology measure, based on self-placement in one of seven categories.

"Same numerical code as "Moderate," but a dummy variable APATHY $=1$ for such responses too.

${ }^{\mathrm{d}}$ CALAMITY: Count of serious adverse events that subject reports have happened to their family. This item was phrased as follows: "At any time during your upbringing, was your family household, or anyone in that household, seriously affected by any of the following things?" The possible choices were, as phrased in the survey: (1) natural disaster (flood, storm, hurricane, tornado, earthquake, etc.); (2) job loss and resulting unemployment lasting more than a month; (3) victim of a major crime (grand theft, felony assault, serious fraud, etc.); (4) major health problem (physical or mental); (5) major accident (car crash, fire, etc.); (6) a death in your family household; and (7) a divorce involving any member(s) of your family household. There was also a space for writing in other events, phrased as "some other serious event that was difficult for your family (please describe it briefly here)," which was very rarely used, but which in all cases we counted as an extra "calamity" if the subject used it. 


\section{Table 1-B. Explanatory Variables Used in the Second Study}

\begin{tabular}{|c|c|c|c|c|c|c|c|c|c|c|}
\hline \multicolumn{11}{|c|}{ Mean, Standard deviation and centiles of noncategorical explanatory variables in the second study $(\mathrm{N}=216)$} \\
\hline & mean & \multicolumn{2}{|c|}{$\begin{array}{r}\text { standard } \\
\text { deviation }\end{array}$} & \multicolumn{2}{|c|}{ 10th centile } & \multicolumn{2}{|c|}{\begin{tabular}{c|}
25 th \\
centile
\end{tabular}} & \begin{tabular}{c|}
$50^{\text {th }}$ \\
centile
\end{tabular} & $\begin{array}{l}\begin{array}{l}75 \text { th } \\
\text { centile }\end{array} \\
\end{array}$ & $\begin{array}{c}90 \text { th } \\
\text { centile }\end{array}$ \\
\hline OWNID_MQ & 12.1 & \multicolumn{2}{|c|}{2.52} & \multicolumn{2}{|c|}{9} & \multicolumn{2}{|c|}{10.5} & 12 & 14 & 16 \\
\hline TRUST $^{\mathrm{a}}$ & 9.21 & \multicolumn{2}{|c|}{2.13} & \multicolumn{2}{|c|}{6} & \multicolumn{2}{|c|}{8} & 9 & 11 & 12 \\
\hline LIES $^{b}$ & 1.85 & \multicolumn{2}{|c|}{1.46} & \multicolumn{2}{|c|}{0} & \multicolumn{2}{|c|}{0.5} & 1.5 & 3 & 4 \\
\hline AGE & 22.8 & \multicolumn{2}{|c|}{4.94} & \multicolumn{2}{|c|}{19} & \multicolumn{2}{|c|}{20} & 21 & 24 & 29 \\
\hline PCTWELF $^{\mathrm{c}}$ & 2.15 & \multicolumn{2}{|c|}{1.72} & \multicolumn{2}{|c|}{0.58} & \multicolumn{2}{|c|}{1.03} & 1.77 & 2.78 & 4.51 \\
\hline LMHV $^{\mathrm{d}}$ & 11.51 & \multicolumn{2}{|c|}{0.48} & \multicolumn{2}{|c|}{11.0} & \multicolumn{2}{|c|}{11.2} & 11.4 & 11.7 & 12.2 \\
\hline $\mathrm{LWI}^{\mathrm{e}}$ & 0.261 & 0.1 & & & 163 & & 95 & 0.255 & 0.313 & 0.400 \\
\hline $\mathrm{UWI}^{\mathrm{f}}$ & 0.290 & 0.1 & & & 158 & & 05 & 0.267 & 0.338 & 0.412 \\
\hline AVGPARID $^{g}$ & 4.433 & 1.2 & & & 3 & & 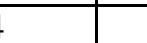 & 4 & 5.5 & 6 \\
\hline HHSIZE $^{\mathrm{h}}$ & 4.10 & 1.3 & & & 3 & & 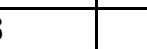 & 4 & 5 & 6 \\
\hline CARPHEAD $^{1}$ & 0.805 & 0.3 & & & 400 & & 28 & 0.750 & 1 & 1 \\
\hline CALAMITY & 1.43 & 1.3 & & & 0 & & 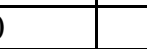 & 1 & 2 & 3 \\
\hline & $\overline{\text { Distributi }}$ & is of cate & ric & lexpl & natory & aria & les used in & the second & udy & \\
\hline OWNID_SR & $\begin{array}{c}\text { Very } \\
\text { Liberal } \\
(1)\end{array}$ & $\begin{array}{l}\text { Liberal } \\
\text { (2) }\end{array}$ & & $\begin{array}{l}\text { pere } \\
\text { peral } \\
3 \text { ) }\end{array}$ & $\begin{array}{l}\text { Moder } \\
\text { (4) }\end{array}$ & & $\begin{array}{c}\text { Some } \\
\text { Conserv } \\
(5)\end{array}$ & $\begin{array}{l}\text { Conserv } \\
\text { (6) }\end{array}$ & $\begin{array}{c}\text { Very } \\
\text { Conserv } \\
(7)\end{array}$ & $\begin{array}{l}\text { Don't } \\
\text { Know } \\
\left(4^{*}\right)\end{array}$ \\
\hline & $3.2 \%$ & $10.6 \%$ & & $.9 \%$ & $18.5^{\circ}$ & & $17.6 \%$ & $13.0 \%$ & $3.7 \%$ & $19.4 \%$ \\
\hline Female & & FEN & LE & $=1$ & & & & If $=$ & Male & \\
\hline & & & $4 \%$ & & & & & & $6 \%$ & \\
\hline $\begin{array}{l}\text { Race and } \\
\text { Ethnicity }\end{array}$ & WHI & $E=1$ & & $\overline{B L A}$ & $\overline{\mathrm{CK}}=1$ & & ASI & $\overline{A N}=1$ & $\begin{array}{r}\text { If all = } \\
\text { (mostly }\end{array}$ & $\begin{array}{l}\text { others } \\
\text { ispanic) }\end{array}$ \\
\hline (3 Dummies) & & & & & $.4 \%$ & & & $.2 \%$ & & \\
\hline $\begin{array}{c}\text { Family } \\
\text { Religion }\end{array}$ & $\begin{array}{r}\text { PROTI } \\
\text { (Prot }\end{array}$ & $\begin{array}{l}M=1 \\
\operatorname{tant})\end{array}$ & & $\begin{array}{r}\overline{\mathrm{CATH}} \\
(\mathrm{Ca}\end{array}$ & $\begin{array}{l}\text { FAM = } \\
\text { holic) }\end{array}$ & & $\begin{array}{r}\text { BUDD } \\
(\mathrm{Bu}\end{array}$ & $\begin{array}{l}\text { FAM = 1 } \\
\text { ddhist) }\end{array}$ & If all $=$ & others \\
\hline (3Dummies) & & & & & $.4 \%$ & & & $.5 \%$ & & \\
\hline $\begin{array}{l}\text { Max of Parents' } \\
\text { Education }\end{array}$ & $\begin{array}{l}\text { PARH } \\
\text { (at leas }\end{array}$ & $\begin{array}{l}\mathrm{CH}=1 \\
\text { ls deg) }\end{array}$ & & $\begin{array}{l}\text { PARC } \\
\text { least }\end{array}$ & $\begin{array}{l}\text { OLL }=1 \\
\text {-yr coll d }\end{array}$ & & $\begin{array}{r}\text { PARG } \\
\text { (gradu }\end{array}$ & $\begin{array}{l}\text { RAD = 1 } \\
\text { late deg) }\end{array}$ & $\begin{array}{l}\text { If all }= \\
\text { (almos }\end{array}$ & $\begin{array}{l}\text { other } \\
1 \text { no hs) }\end{array}$ \\
\hline (3 Dummies) & & & & & $6 \%$ & & & $.6 \%$ & & \\
\hline High School was & & PUB & $\mathrm{CH}$ & & & & If $=$ & , parochial, & rivate and/c & ome \\
\hline Public & & & $0 \%$ & & & & & & $0 \%$ & \\
\hline Union Member & & $\mathrm{HHU}$ & ION & $=1$ & & & & 0 , no union & nember in $\mathrm{f}$ & iily \\
\hline in Family & & & $5 \%$ & & & & & & $5 \%$ & \\
\hline Family Has & & $\mathrm{HHV}$ & $\overline{E L F}$ & $=1$ & & & If $=0, \mathrm{n}$ & ever any pub & ic assistanc & family \\
\hline $\begin{array}{l}\text { Received Public } \\
\text { Assistance }\end{array}$ & & & $8 \%$ & & & & & & $2 \%$ & \\
\hline
\end{tabular}

Variables with the same name as in the first study have the same meaning here. New variables are:

${ }^{a}$ TRUST: Trust of authority measure based on three item responses (see text for details).

${ }^{b}$ LIES: Image management measure (SDR) based on ten item responses (see text for details).

${ }^{\text {cdef }}$ These are constructed from economic characteristics (from the 2000 U.S. census) of the zip code areas subjects' families lived in during the subjects' last year of high school. PCTWELF is the percentage of households receiving public assistance income. Letting Q3HV, MHV and Q1HV be the third quartile, median and first quartiles of the distributions of the value of owner-occupied housing in the zip code areas, LMHV $=\ln (\mathrm{MHV}), \mathrm{LWI}=\mathrm{LMHV}-$ $\ln (\mathrm{Q} 1 \mathrm{HV})$ and $\mathrm{UWI}=\ln (\mathrm{Q} 3 \mathrm{HV})-\mathrm{LMHV}$.

${ }^{g}$ AVGPARID: Average of parents' ideology based one subject's placement in seven response categories.

${ }^{h}$ HHSIZE: Number of persons (including self) in family's household in last year of high school.

'CARPHEAD: Motor vehicles per person in family's household in last year of high school. 


\section{Table 2. Relationships Between Ex-ante Beliefs Within Each Study}

\begin{tabular}{|c|c|c|}
\hline \multirow{2}{*}{$\begin{array}{c}\text { Type of ex-ante belief } \\
\text { difference }\end{array}$} & \multicolumn{2}{|c|}{$\begin{array}{l}\text { P-values of t-tests (T), sign tests (S) and rank-sum tests (RS) of } \\
\text { the hypothesis that various ex-ante belief differences are zero } \\
\text { (one-sample tests based on within-subject differences) }\end{array}$} \\
\hline & $\begin{array}{c}\text { First Study } \\
(\text { Yr 2000, N=128) }\end{array}$ & $\begin{array}{c}\text { Second Study } \\
\text { (Yr 2002-03, N=216) }\end{array}$ \\
\hline $\begin{array}{l}\text { price minus quantity } \\
\text { ANTE_P - ANTE_Q }\end{array}$ & $\begin{array}{c}\text { mean difference: } 0.055 \\
\text { T: } p=0.34 \\
\text { S: } p=0.45 \\
\text { RS: } p=0.34\end{array}$ & $\begin{array}{c}\text { mean difference: } 0.48 \\
\text { T: } p<0.0001 \\
\text { S: } p<0.0001 \\
\text { RS: } p<0.0001\end{array}$ \\
\hline $\begin{array}{l}\text { price minus efficiency } \\
\text { ANTE_P - ANTE_E }\end{array}$ & $\begin{array}{c}\text { mean difference: } 0.016 \\
\text { T: } p=0.82 \\
\text { S: } p=0.78 \\
\text { RS: } p=0.91\end{array}$ & $\begin{array}{c}\text { mean difference: } 0.54 \\
\text { T: } p<0.0001 \\
\text { S: } p<0.0001 \\
\text { RS: }<0.0001\end{array}$ \\
\hline $\begin{array}{l}\text { quantity minus efficiency } \\
\text { ANTE_Q - ANTE_E }\end{array}$ & $\begin{array}{c}\text { mean difference: }-0.039 \\
\text { T: } p=0.55 \\
\text { S: } p=0.34 \\
\text { RS: } p=0.48\end{array}$ & $\begin{array}{c}\text { mean difference: } 0.060 \\
\text { T: } p=0.42 \\
\text { S: } p=0.55 \\
\text { RS: } p=0.39\end{array}$ \\
\hline
\end{tabular}

Table 3. Significant Effects of Observed Evidence on Changes in Beliefs in the Two Studies

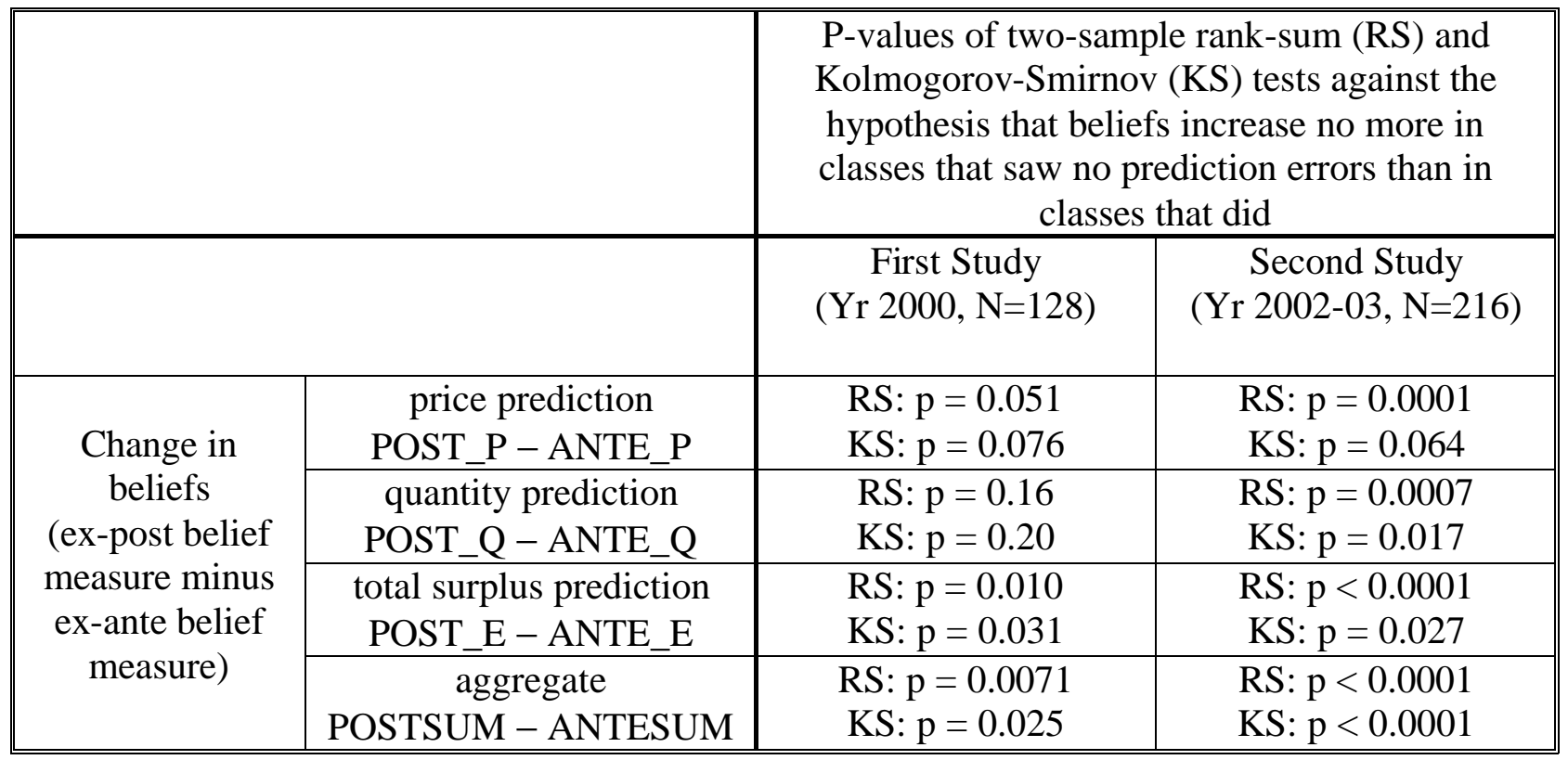


Table 4. Relationships Between Beliefs and Ideology Measures in the Two Studies: Bivariate Results

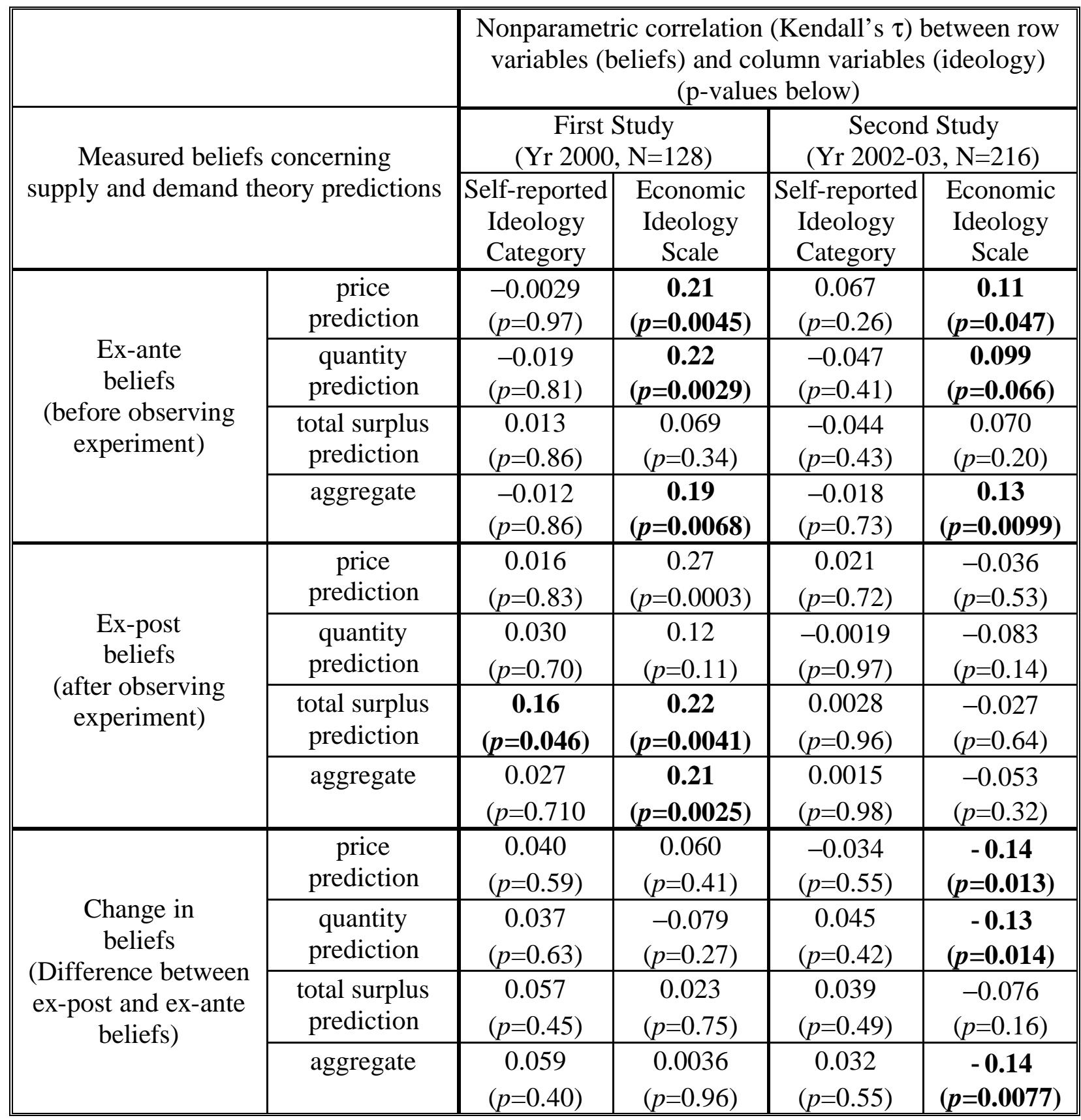

Bold font indicates that correlation is significantly different from zero at ten percent or better. 
Table 5. Multivariate Analysis of Aggregate Belief Variables in the First Study

\begin{tabular}{|c|c|c|c|c|}
\hline \multirow{2}{*}{\multicolumn{2}{|c|}{ Regressors }} & \multicolumn{3}{|c|}{$\begin{array}{l}\text { Standardized effect estimates }{ }^{\mathrm{a}} \text { and their p-values in ordered } \\
\text { logit models of these dependent variables in the First Study } \\
\text { (Year } 2000, \mathrm{~N}=128)\end{array}$} \\
\hline & & $\begin{array}{l}\text { Ex ante beliefs } \\
\text { (ANTESUM) }\end{array}$ & $\begin{array}{l}\text { Ex post beliefs } \\
\text { (POSTSUM) }\end{array}$ & $\begin{array}{c}\text { Change in beliefs } \\
\text { (DELTASUM) }\end{array}$ \\
\hline \multicolumn{2}{|c|}{ Economic ideology scale (OWNID_MQ) } & $0.29, p=0.0096$ & $0.27, p=0.023$ & $-0.092, p=0.39$ \\
\hline \multicolumn{2}{|c|}{ Observed any prediction errors in the experiment } & $-0.031, p=0.80$ & $-0.40, p=0.0021$ & $-0.26, p=0.032$ \\
\hline \multicolumn{2}{|c|}{...Observed more than one prediction error } & $0.055, \mathrm{p}=0.64$ & $0.012, \mathrm{p}=0.92$ & $0.010, p=0.93$ \\
\hline \multicolumn{2}{|c|}{ Female } & $-0.17, p=0.074$ & $0.14, \mathrm{p}=0.17$ & $0.21, p=0.028$ \\
\hline \multicolumn{2}{|l|}{ Age } & $0.090, \mathrm{p}=0.38$ & $-0.0041, p=0.97$ & $-0.065, p=0.51$ \\
\hline \multirow{5}{*}{$\begin{array}{l}\text { Family income class } \\
\text { category }\end{array}$} & 22,000 to 50,000 & $-0.20, p=0.17$ & $-0.16, p=0.29$ & $0.063, p=0.51$ \\
\hline & 50,000 to 75,000 & $-0.12, p=0.41$ & $0.048, p=0.76$ & $0.15, p=0.29$ \\
\hline & 75,000 to 100,000 & $0.053, p=0.71$ & $0.050, p=0.74$ & $0.022, p=0.87$ \\
\hline & greater than 100,000 & $-0.028, p=0.87$ & $-0.058, p=0.74$ & $-0.013, p=0.93$ \\
\hline & jointly significant? & no, $p=0.41$ & no, $\mathrm{p}=0.45$ & no, $p=0.70$ \\
\hline \multirow{4}{*}{ Race/Ethnicity } & White & $-0.019, p=0.90$ & $-0.030, p=0.84$ & $0.054, \mathrm{p}=0.71$ \\
\hline & Black & $0.11, \mathrm{p}=0.37$ & $0.13, \mathrm{p}=0.33$ & $-0.0069, \mathrm{p}=0.95$ \\
\hline & Asian & $0.0090, p=0.94$ & $-0.032, p=0.80$ & $-0.0116, p=0.92$ \\
\hline & jointly significant? & no, $p=0.73$ & no, $\mathrm{p}=0.59$ & no, $\mathrm{p}=0.96$ \\
\hline \multirow{4}{*}{$\begin{array}{l}\text { Education of most } \\
\text { educated parent }\end{array}$} & at least high school & $0.0060, p=0.95$ & $0.0043, p=0.97$ & $-0.062, \mathrm{p}=0.53$ \\
\hline & at least 4-year college & $0.070, \mathrm{p}=0.57$ & $-0.15, p=0.27$ & $-0.11, p=0.35$ \\
\hline & graduate degree & $0.019, \mathrm{p}=0.87$ & $0.13, \mathrm{p}=0.28$ & $0.068, p=0.53$ \\
\hline & jointly significant? & no, $\mathrm{p}=0.91$ & no, $\mathrm{p}=0.62$ & no, $\mathrm{p}=0.65$ \\
\hline \multicolumn{2}{|c|}{ Count of adverse events in family's history } & $-0.0093, p=0.93$ & $0.11, p=0.32$ & $0.083, p=0.42$ \\
\hline \multicolumn{2}{|c|}{ Attended public high school } & $-0.060, p=0.54$ & $-0.0071, p=0.95$ & $0.036, p=0.71$ \\
\hline \multicolumn{2}{|c|}{ Union member in family } & $-0.032, p=0.76$ & $-0.30, p=0.0069$ & $-0.13, p=0.19$ \\
\hline \multicolumn{2}{|c|}{ Family owns stocks } & $-0.018, p=0.88$ & $0.10, \mathrm{p}=0.41$ & $0.081, \mathrm{p}=0.47$ \\
\hline \multicolumn{2}{|l|}{ Log likelihood } & -195.08 & -153.23 & -225.85 \\
\hline \multicolumn{2}{|l|}{${ }^{\mathrm{b}}$ Estrella pseudo- ${ }^{2}$} & 0.1548 & 0.3083 & 0.1497 \\
\hline
\end{tabular}

Bold font indicates that effect is significantly different from zero at ten percent or better.

"The "standardized effect" is not the parameter estimate divided by its estimated standard error. Rather, it is the change in the latent variable (or index function) of the ordered logit model, expressed in units of its own standard deviation, due to a change in one sample standard deviation of the indicated explanatory variable. This makes the practical significance of the explanatory variables more comparable across the rows of the table.

bEstrella's (1998) pseudo- $\mathrm{R}^{2}$ is defined as $1-[\mathrm{LL} / \mathrm{LL}(0)]^{-2 \mathrm{LL}(0) / \mathrm{N}}$, where LL is the log likelihood of the model with all regressors and intercepts, $\mathrm{LL}(0)$ is the $\log$ likelihood with only the intercepts, and $\mathrm{N}$ is the number of observations. 


\section{Table 6. Multivariate Analysis of Aggregate Belief Variables in the Second Study}

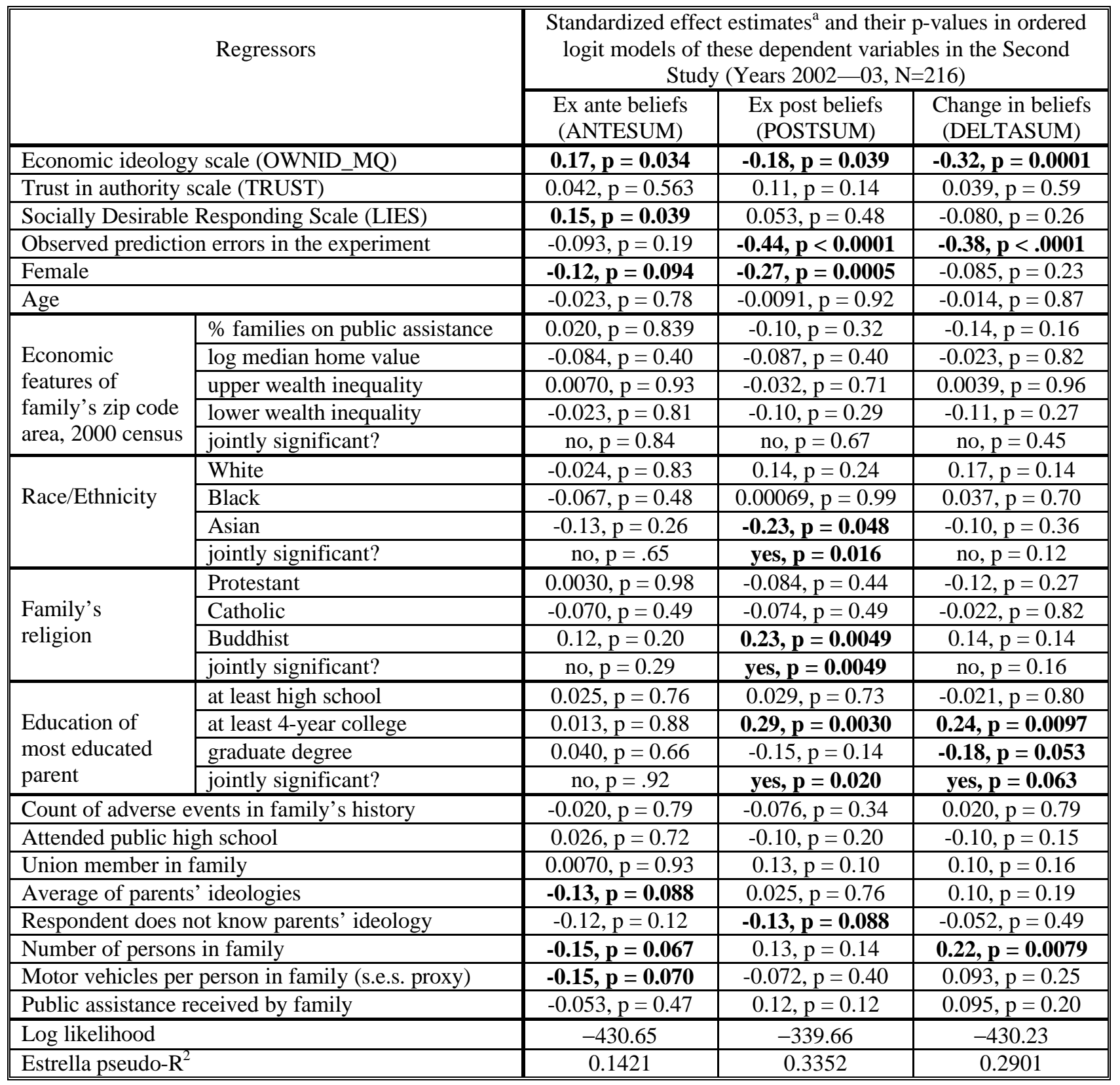

Bold font indicates that effect is significantly different from zero at ten percent or better.

"The "standardized effect" is not the parameter estimate divided by its estimated standard error. Rather, it is the change in the latent variable (or index function) of the ordered logit model, expressed in units of its own standard deviation, due to a change in one sample standard deviation of the indicated explanatory variable. This makes the practical significance of the explanatory variables more comparable across the rows of the table.

'Estrella's (1998) pseudo- $\mathrm{R}^{2}$ is defined as $1-[\mathrm{LL} / \mathrm{LL}(0)]^{-2 \mathrm{LL}(0) / \mathrm{N}}$, where LL is the log likelihood of the model with all regressors and intercepts, $\mathrm{LL}(0)$ is the $\log$ likelihood with only the intercepts, and $\mathrm{N}$ is the number of observations. 


\section{Table 7. Multivariate Analysis of Ideology and Ex-ante Beliefs, Conditioned on the Same Set of Exogenous Explanatory Variables, in the Second Study}

\begin{tabular}{|c|c|c|c|}
\hline & \multirow[t]{2}{*}{ Regressors } & \multicolumn{2}{|c|}{$\begin{array}{l}\text { Standardized effect estimates }{ }^{\mathrm{a}} \text { and their p-values in ordered } \\
\text { logit model of ex ante beliefs and OLS model of economic } \\
\text { ideology in the Second Study (Years 2002-03, N=216) }\end{array}$} \\
\hline & & $\begin{array}{c}\text { Ex ante beliefs } \\
\text { (ANTESUM) }\end{array}$ & $\begin{array}{l}\text { Economic ideology } \\
\text { (IDEOL_MQ) }\end{array}$ \\
\hline \multicolumn{2}{|l|}{ Female } & $-0.11, p=0.11$ & $0.080, p=0.22$ \\
\hline \multicolumn{2}{|l|}{ Age } & $-0.0012, p=0.99$ & $0.16, p=0.036$ \\
\hline \multirow{5}{*}{$\begin{array}{l}\text { Economic } \\
\text { features of } \\
\text { family's zip code } \\
\text { area, } 2000 \text { census }\end{array}$} & $\%$ families on public assistance & $0.020, p=0.83$ & $0.067, p=0.45$ \\
\hline & log median home value & $-0.066, p=0.51$ & $0.049, p=0.59$ \\
\hline & upper wealth inequality & $-0.013, p=0.87$ & $-0.078, p=0.30$ \\
\hline & lower wealth inequality & $0.018, p=0.85$ & $-0.026, p=0.77$ \\
\hline & jointly significant? & no, $p=0.91$ & no, $p=0.72$ \\
\hline \multirow{4}{*}{ Race/Ethnicity } & White & $0.028, p=0.80$ & $0.30, p=0.0035$ \\
\hline & Black & $-0.066, p=0.49$ & $0.015, \mathrm{p}=0.87$ \\
\hline & Asian & $-0.18, p=0.11$ & $-0.12, p=0.25$ \\
\hline & jointly significant? & no, $p=0.20$ & yes, $p=0.0002$ \\
\hline \multirow{4}{*}{$\begin{array}{l}\text { Family's } \\
\text { religion }\end{array}$} & Protestant & $-0.048, p=0.64$ & $-0.052, p=0.58$ \\
\hline & Catholic & $-0.075, p=0.46$ & $0.017, p=0.85$ \\
\hline & Buddhist & $0.11, p=0.26$ & $0.064, p=0.48$ \\
\hline & jointly significant? & no, $p=0.36$ & no, $p=0.70$ \\
\hline \multirow{4}{*}{$\begin{array}{l}\text { Education of } \\
\text { most educated } \\
\text { parent }\end{array}$} & high school or more & $0.028, p=0.73$ & $0.038, p=0.61$ \\
\hline & 4-year college or more & $-0.020, p=0.83$ & $-0.052, p=0.53$ \\
\hline & graduate degree & $0.061, p=0.50$ & $0.095, p=0.26$ \\
\hline & jointly significant? & no, $p=0.90$ & no, $p=0.70$ \\
\hline \multicolumn{2}{|c|}{ Count of adverse events in family's history } & $-0.064, p=0.40$ & $-0.027, p=0.70$ \\
\hline \multicolumn{2}{|c|}{ Attended public high school } & $0.031, p=0.67$ & $-0.00065, p=0.99$ \\
\hline \multicolumn{2}{|c|}{ Union member in family } & $-0.0053, p=0.94$ & $-0.092, p=0.17$ \\
\hline \multicolumn{2}{|c|}{ Average of parents' ideologies } & $-0.11, p=0.16$ & $0.037, p=0.60$ \\
\hline \multicolumn{2}{|c|}{ Respondent does not know parents' ideology } & $-0.09, p=0.22$ & $-0.0020, p=0.98$ \\
\hline \multicolumn{2}{|c|}{ Number of persons in family } & $-0.15, p=0.060$ & $0.027, p=0.72$ \\
\hline \multicolumn{2}{|c|}{ Motor vehicles per person in family (s.e.s. proxy) } & $-0.12, p=0.13$ & $0.20, p=0.0066$ \\
\hline \multicolumn{2}{|c|}{ Public assistance received by family } & $-0.052, p=0.48$ & $-0.057, \mathrm{p}=0.40$ \\
\hline \multicolumn{2}{|c|}{ Log likelihood } & -436.26 & NA \\
\hline \multicolumn{2}{|l|}{$\mathrm{R}^{2}$} & $\begin{array}{c}{\left.\text { (Estrella pseudo- }{ }^{2}\right)^{b}}^{0.0949}\end{array}$ & 0.2739 \\
\hline
\end{tabular}

Bold font indicates that effect is significantly different from zero at ten percent or better.

"The "standardized effect" is not the parameter estimate divided by its estimated standard error. Rather, it is the change in the latent variable (or index function) of the ordered logit model, expressed in units of its own standard deviation, due to a change in one sample standard deviation of the indicated explanatory variable. This makes the practical significance of the explanatory variables more comparable across the rows of the table.

${ }^{b}$ Estrella's (1998) pseudo- $\mathrm{R}^{2}$ is defined as $1-[\operatorname{LL} / \operatorname{LL}(0)]^{-2 \mathrm{LL}(0) / \mathrm{N}}$, where LL is the log likelihood of the model with all regressors and intercepts, $\operatorname{LL}(0)$ is the log likelihood with only the intercepts, and $\mathrm{N}$ is the number of observations. 
Table 8. Best Sets of Exogenous Explanatory Variables for Ex-ante Beliefs and Ideology, by Aikaki (AIC) and Bayes (BIC) Information Criteria, in the Second Study

\begin{tabular}{|c|c|c|c|c|}
\hline \multirow[t]{3}{*}{ Regressors } & \multicolumn{4}{|c|}{$\begin{array}{l}\text { Standardized effect estimates }{ }^{\mathrm{a}} \text { and their p-values in } \\
\text { ordered logit models of antesum and OLS model of } \\
\text { ideology in the Second Study (Years 2002-03, N=216) }\end{array}$} \\
\hline & \multicolumn{2}{|c|}{$\begin{array}{l}\text { Ex Ante Beliefs } \\
\text { (ANTESUM) }\end{array}$} & \multicolumn{2}{|c|}{$\begin{array}{l}\text { Economic Ideology } \\
\text { (OWNID_MQ) }\end{array}$} \\
\hline & $\begin{array}{l}\text { selected by } \\
\text { BIC }\end{array}$ & $\begin{array}{l}\text { selected by } \\
\text { AIC }\end{array}$ & $\begin{array}{l}\text { selected by } \\
\text { BIC }\end{array}$ & $\begin{array}{l}\text { selected by } \\
\text { AIC }\end{array}$ \\
\hline Number of Persons in Family & $\begin{array}{c}-0.15 \\
p=0.025\end{array}$ & $\begin{array}{c}-0.12 \\
p=0.097\end{array}$ & $\begin{array}{c}\text { Not } \\
\text { Selected }\end{array}$ & $\begin{array}{c}\text { Not } \\
\text { Selected }\end{array}$ \\
\hline Female & $\begin{array}{c}\text { Not } \\
\text { Selected }\end{array}$ & $\begin{array}{c}-0.12 \\
p=0.069\end{array}$ & $\begin{array}{c}\text { Not } \\
\text { Selected }\end{array}$ & $\begin{array}{l}\text { Not } \\
\text { Selected }\end{array}$ \\
\hline Family Religion is Buddhist & $\begin{array}{c}\text { Not } \\
\text { Selected }\end{array}$ & $\begin{array}{c}0.15 \\
p=0.071 \\
\end{array}$ & $\begin{array}{c}\text { Not } \\
\text { Selected } \\
\end{array}$ & $\begin{array}{c}\text { Not } \\
\text { Selected } \\
\end{array}$ \\
\hline Asian & $\begin{array}{c}\text { Not } \\
\text { Selected }\end{array}$ & $\begin{array}{c}-0.17 \\
p=0.045\end{array}$ & $\begin{array}{c}\text { Not } \\
\text { Selected }\end{array}$ & $\begin{array}{c}\text { Not } \\
\text { Selected }\end{array}$ \\
\hline Age & $\begin{array}{c}\text { Not } \\
\text { Selected }\end{array}$ & $\begin{array}{c}\text { Not } \\
\text { Selected }\end{array}$ & $\begin{array}{c}0.14 \\
p=0.021\end{array}$ & $\begin{array}{c}0.14 \\
p=0.021\end{array}$ \\
\hline White & $\begin{array}{l}\text { Not } \\
\text { Selected }\end{array}$ & $\begin{array}{c}\text { Not } \\
\text { Selected }\end{array}$ & $\begin{array}{c}0.33 \\
p<0.0001\end{array}$ & $\begin{array}{c}0.32 \\
p<0.0001\end{array}$ \\
\hline $\begin{array}{l}\text { Motor vehicles per person in family } \\
\text { (s.e.s. proxy) }\end{array}$ & $\begin{array}{c}\text { Not } \\
\text { Selected }\end{array}$ & $\begin{array}{c}\text { Not } \\
\text { Selected }\end{array}$ & $\begin{array}{c}0.21 \\
p=0.0010\end{array}$ & $\begin{array}{c}0.21 \\
p=0.0010\end{array}$ \\
\hline $\begin{array}{l}\text { Upper wealth inequality in family's } \\
\text { zip code area, } 2000 \text { census }\end{array}$ & $\begin{array}{l}\text { Not } \\
\text { Selected }\end{array}$ & $\begin{array}{c}\text { Not } \\
\text { Selected }\end{array}$ & $\begin{array}{c}\text { Not } \\
\text { Selected }\end{array}$ & $\begin{array}{l}-0.085 \\
p=0.16\end{array}$ \\
\hline Union member in family & & & $\begin{array}{c}\text { Not } \\
\text { Selected }\end{array}$ & $\begin{array}{l}-0.095 \\
p=0.12\end{array}$ \\
\hline $\mathrm{R}^{2}$ & $\begin{array}{l}(\text { Estrella } \\
\left.\text { pseudo- }^{2}\right)^{\mathrm{b}} \\
0.0230\end{array}$ & $\begin{array}{c}(\text { Estrella } \\
\left.\text { pseudo- } \mathrm{R}^{2}\right)^{\mathrm{b}} \\
0.0580\end{array}$ & 0.23 & 0.24 \\
\hline
\end{tabular}

aThe "standardized effect" is not the parameter estimate divided by its estimated standard error. Rather, it is the change in the latent variable (or index function) of the ordered logit model, expressed in units of its own standard deviation, due to a change in one sample standard deviation of the indicated explanatory variable. This makes the practical significance of the explanatory variables more comparable across the rows of the table.

bestrella's (1998) pseudo- $\mathrm{R}^{2}$ is defined as $1-[\mathrm{LL} / \mathrm{LL}(0)]^{-2 \mathrm{LL}(0) / \mathrm{N}}$, where LL is the log likelihood of the model with all regressors and intercepts, LL(0) is the log likelihood with only the intercepts, and $\mathrm{N}$ is the number of observations. 